\title{
Modelling of surface and inner wall temperatures in the analysis of courtyard thermal performances in Mediterranean climates
}

\author{
V.P. López-Cabeza $\quad{ }^{a}$, F.J. Carmona-Molerob ${ }^{b}$, S. Rubino ${ }^{b}$, C. Rivera-Gómez ${ }^{a}$, E.D. Fernández-Nietoc, \\ C. Galán-Marín a and T. Chacón-Rebollo ${ }^{\mathrm{b}}$ \\ aDepartamento de Construcciones Arquitectónicas 1, Instituto Universitario de Arquitectura y Ciencias de la Construcción, Escuela Técnica \\ Superior de Arquitectura, Universidad de Sevilla, Avda. Reina Mercedes, 2, 41012, Seville, Spain; ${ }^{b}$ Departamento de Ecuaciones Diferenciales \\ y Análisis Numérico, Facultad de Matemáticas and Instituto de Matemáticas (IMUS), Universidad de Sevilla, C. Tarfia s/n, 41012, Seville, Spain; \\ 'Departamento de Matemática Aplicada I, Escuela Técnica Superior de Arquitectura, and Instituto de Matemáticas (IMUS), Universidad de \\ Sevilla, Avda. Reina Mercedes, 2, 41012, Seville, Spain
}

\begin{abstract}
Courtyards are an effective passive strategy for improving the energy performance of buildings. However, there is a lack of accurate simulation tools for their thermal performance due to their complex thermodynamics. This paper's contribution is the coupling of a CFD model with a system of differential equations at the walls, governing surface and inner wall temperatures, providing an accurate computation of courtyard thermal performance. On this basis, boundary conditions for the standard Boussinesq equations governing temperatures, wind velocity, and pressure within the courtyard are established. Modelling results are compared with monitored data in two days of different months in a courtyard in Seville (Spain). Simultaneously, simulations carried out by existing software were performed. Resulting data showed more accuracy than existing tools, with a Root Mean Square Error of 1.19 (August) and 1.59 (October), while the corresponding values with ENVI-met were 3.31-3.4, and with Ladybug Tools 2.59-4.49.
\end{abstract}

\section{KEYWORDS}

Courtyards; ENVI-met; numerical model; model evaluation; microclimate simulation

\section{Table of symbols:}

$\begin{array}{ll}\theta & \text { Temperature inside the courtyard } \\ \theta_{\mathrm{in}} & \text { Inner temperature of the wall } \\ \theta_{\mathrm{w}} & \text { Surface temperature of the wall } \\ \theta(x \circ \delta, t) & \text { Air temperature near the wall } \\ \rho_{\mathrm{w}} & \text { Wall density } \\ \mathrm{C}_{\mathrm{w}} & \text { Specific Heat of the wal } \\ \mathrm{V}_{\mathrm{w}} & \text { Wall volume } \\ \mathrm{U}_{\mathrm{ext}} & \text { Transmittance coefficient of the air } \\ \mathrm{A} & \text { Area of the wall } \\ \mathrm{U}_{\mathrm{in}} & \text { Transmittance coefficient of the wall } \\ \epsilon & \text { Emissivity } \\ \sigma & \text { Stefan-Boltzmann constant } \\ \alpha_{\mathrm{w}} & \text { Absorption coefficient } \\ \mathrm{I} & \text { Solar radiation } \\ \mathrm{Q} & \text { Heat transfer } \\ \theta_{\mathrm{s}} & \text { Sky temperature } \\ \mu & \text { Sky function } \\ \mathrm{e} & \text { Wall thickness } \\ \Omega & \text { Domain } \\ \mathrm{T} & \text { Final time } \\ \mathrm{L} & \text { Characteristic flow length }\end{array}$

Characteristic maximum temperature difference

Air velocity field

Pressure

Viscosity

$\mathrm{RH} \quad$ Relative Humidity

$\mathrm{I}_{\alpha} \quad$ Thermal expansion coefficient

$\theta_{\text {ref }} \quad$ Reference temperature

$\alpha \quad$ Thermal diffusion

g Gravity constant

$\rho_{0} \quad$ Reference density

$\Gamma_{i} \quad$ Boundaries of the system

$\mathrm{u}_{\mathrm{s}} \quad$ Wind velocity at the upper part of the court-

yard

Pr Prandtl number

Ra Rayleigh number

AR Aspect Ratio of the courtyard (hmax/W)

$\mathrm{h}_{\max } \quad$ Maximum height of the courtyard

W Width of the courtyard

$R^{2} \quad$ Coefficient of determination

RMSE Root Mean Square Error

CONTACT C. Galán-Marín cgalan@us.es Departamento de Construcciones Arquitectónicas 1, Instituto Universitario de Arquitectura y Ciencias de la Construcción, Escuela Técnica Superior de Arquitectura, Universidad de Sevilla, Avda. Reina Mercedes, 2, 41012, Seville, 
RMSES

RMSEU

MAPE

Systematic Root Mean Square Error

Unsystematic Root Mean Square Error

Mean Absolute Percentage Error

\section{Introduction}

Climate change is one of the main challenges our society is facing nowadays. Projected global mean surface temperature will rise over all possible scenarios and heat waves will occur more often and last longer (IPCC 2014). Moreover, this problem will be intensified in urban environments, where heat island effect may increase urban microclimate up to $10^{\circ} \mathrm{C}$ (Santamouris and Yun 2020), reducing inhabitants' comfort and increasing the energy consumption of buildings to meet cooling necessities (Santamouris et al. 2001). Aiming at mitigating global warming effects and impacts, the decarbonization and implementation of climate-resilient design solutions in buildings are critical. They are responsible for almost $40 \%$ of energy- and process-related emissions, taking climate action in buildings is among the most cost-effective strategies (IEA/UN 2019).

Energy consumption reduction in buildings is possible through advanced design, as it is possible to achieve zero energy consumption buildings or even positive. Furthermore, through the design of climate-resilient urban environments, it is possible to reduce the heat island effect (Srebric, Heidarinejad, and Liu 2015). From the analysis of traditional architecture that is adapted to specific climate conditions, it is possible to learn climate-resilient strategies for new constructions and increase user comfort (Chandel, Sharma, and Marwah 2016). The design of transitional spaces such as courtyards is one of the best strategies that can reduce energy consumption as well as temper the outdoor climatic conditions creating a microclimate in the courtyard that also helps to reduce the heat island effect in the urban scale (Kubota et al. 2017; Rojas, Galán-Marín, and Fernández-Nieto 2012; Rojas-Fernández et al. 2017). However, a deep understanding of the thermodynamic effects that occur in the courtyards, i.e. stratification, convection, and flow patterns, is needed to decide the optimum design (Rojas, Galán-Marín, and Fernández-Nieto 2012). Plenty of factors take part in the performance of a courtyard, not only its geometry but also shading elements, vegetation, water elements and the albedo of the surfaces among others (Abdulkareem 2016; Ghaffarianhoseini, Berardi, and Ghaffarianhoseini 2015). A simulation procedure able to incorporate all these factors used during the design process would be helpful to make decisions about the project, based on accurate data. Furthermore, if the simulated microclimate is incorporated into an energy modelling tool, it would accurately predict the energy consumption of the building.

Although there are many simulation tools to predict the energy performance of buildings, the complex thermodynamic effects that happen in courtyards require simulation tools with high computational resources and thousands of simulation hours to calculate and simulate a representative period, based on CFD (Computational Fluid Dynamics) and finite elements (Blocken et al. 2011). In the analysis performed by Rojas et al. (Rojas-Fernández et al. 2018), the main available simulation tools are analysed concerning their capacity to simulate transitional spaces from the point of view of a professional of the building sector. They found that there is no available software that meets all requirements for this reliable microclimate simulation. Even though some tools have been developed in recent years concerning the urban microclimate simulation, the efforts are focused on the integrated systemic approach, which includes urban modelling of microclimatic effects, transient heat flows, plants and equipment and occupant behaviour (Mauree et al. 2019). However, this approach requires a huge computational power and may lack accuracy in favour of other aspects such as managing a huge amount of data. This is the case of one of the most widely used dynamic tools for the simulation of urban microclimates: ENVImet (Tsoka, Tsikaloudaki, and Theodosiou 2018). ENVImet is a three-dimensional non-hydrostatic model for the simulation of surface-plant-air interactions ("ENVI-Met" 2019). The software integrates an atmospheric model, vegetation model, soil model, and the built environment and building systems. However, it has some limitations: first, it needs a great amount of time to provide results given the integration of such quantity of data. Second, it is developed for urban microclimates where wind causes turbulent situations. But in the case of courtyards, generally protected from the wind, the thermodynamic effects are governed by convection patterns. Thus, existing CFD models usually don't provide accurate results.

The Ladybug Tools are an emerging methodology that combines different simulation engines into the same graphical interface of Grasshopper for Rhinoceros (Sadeghipour Roudsari, Pak, and Smith 2013). The Ladybug Tools allows the connection of the building energy simulation by EnergyPlus and the microclimate CFD calculation by OpenFOAM. It is open source, being continuously enhanced by the research community. It has some limitations too. First, there is only one OpenFOAM heat transfer solver linked to the Ladybug interface; thus, it may not be the best one for outdoor microclimate analysis. Second, although the different simulation engines are linked through Grasshopper, it holds the potential to 


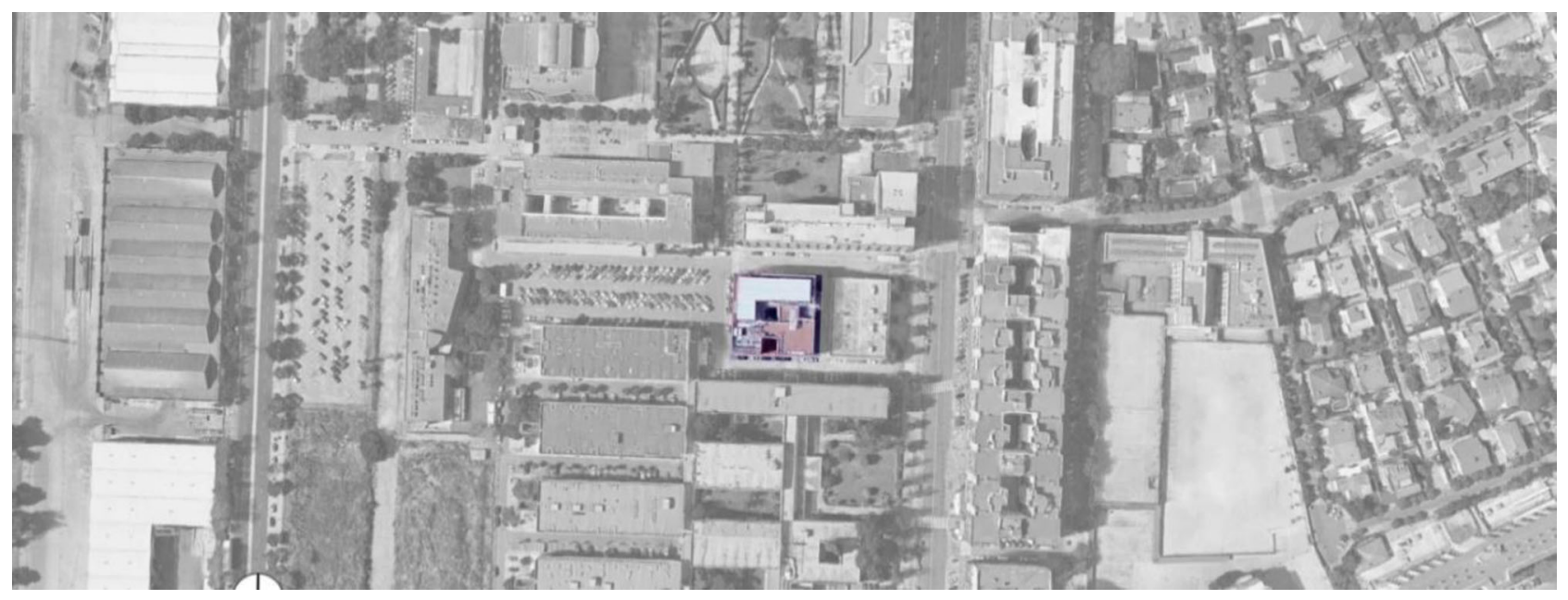

Figure 1. Location of the building.

increase error as data is passed from one engine to the other.

In this context, it is necessary the development of new model specifically created for the performance simulation of courtyards, aiming to gain accuracy and computational speed. It should take into account buoyancy, solar radiation, wind and thermal exchange with the surrounding building. Once developed, it should be easy to implement in a 'hybrid' simulation workflow (Elwy et al. 2018; Mackey et al. 2017) to link with other simulation engines if needed. This paper develops and validates a novel numerical procedure to evaluate the courtyard thermal performance as a climate-resilient strategy of buildings. The proposed model is developed in FreeFEM software and validated in a case study located in the city of Seville, Spain. Moreover, the model accuracy is compared with other existing commercial tools, such as the previously described ENVI-met and the Ladybug tools. Both are also contrasted with the monitored data.

The paper is structured as follows. First, the case study for data collection and model validation is characterized. Second, the methodology is presented, which is divided into three sections: section 3.1 shows the novel coupled model for courtyard; section 3.2 details the data collection procedure for model validation; and section 3.3 provides details about the comparison with existing simulation tools. Third, the results of novel procedure and existing simulation tools are presented and discussed, highlighting the accuracy of each of the simulation tools described. Finally, conclusions are reported, and future research steps are described.

\section{Definition and characterization of the case study for model validation}

The selected case study to test the proposed numerical model is the courtyard of the CITIUS building of the University of Seville. This city (Spain $37^{\circ} 17^{\prime} 01 / 1 \mathrm{~N}$ $5^{\circ} 55^{\prime} 20 / \mathrm{W}$, elevation $42 \mathrm{~m}$ a.s.l.) is Csa in the Köppen classification (Kottek et al. 2006), characterized by hot and dry summers with mean temperatures of $36^{\circ} \mathrm{C}$ in July and mild winters with mean temperatures of $10.9^{\circ} \mathrm{C}$ in January. The mean annual precipitation is $539 \mathrm{~mm}$ ("Resúmenes Climatológicos - España - Anuales - Agencia Estatal de Meteorología - AEMET. Gobierno de España" 2018). The building is located in an urban area of a high density of mid-rise constructions (Figure 1).

The courtyard, graphically defined in Figure 2 and Figure 3 , has an approximately squared floor plan of $7.3 \times 6.6$ and $14.0 \mathrm{~m}$ height. To define the geometry of a courtyard, the concept Aspect Ratio is used, which is defined as the relation between the width and the height as follows:

$$
\mathrm{AR}=\frac{\mathrm{h}_{\max }}{\mathrm{W}}
$$

where $h_{\max }$ is the maximum height and $W$ is the width of the courtyard.

The aspect ratio of the case study courtyard is 2.02 . The walls' coating is white cement mortar. The thermal transmittance of the wall is $0.474 \mathrm{~W} / \mathrm{m}^{2} \mathrm{~K}$. There are small glazed openings distributed sporadically in the walls. There is no shading element or vegetation in the courtyard.

The interior composition of all walls is illustrated in Figure 4, needed to predict the temperature of the surfaces. They are cavity walls; the outdoor layer consists of $11.5 \mathrm{~cm}$ brick coated by $1 \mathrm{~cm}$ white mortar. The air cavity separating the outdoor layer from the inside functions as an insulator and it is followed by more layers of insulation material. Consequently, the rest of the layers of the wall are not relevant for temperature purposes because the inner temperature that affects the surface temperature is independent of the indoor. Therefore, a reduction 


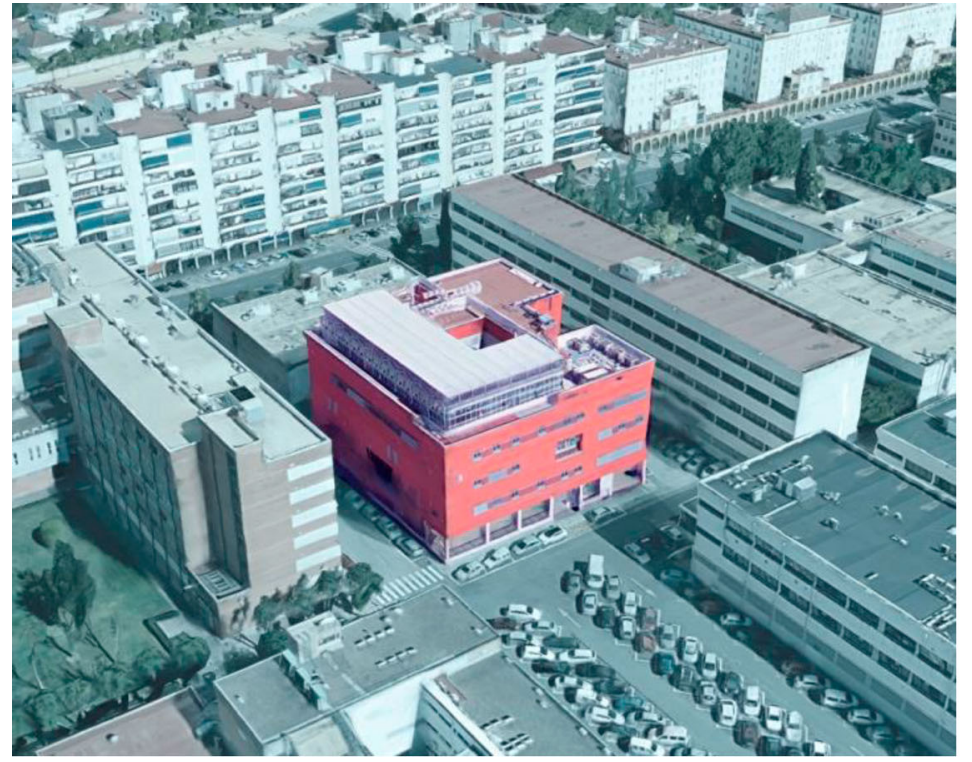

a.

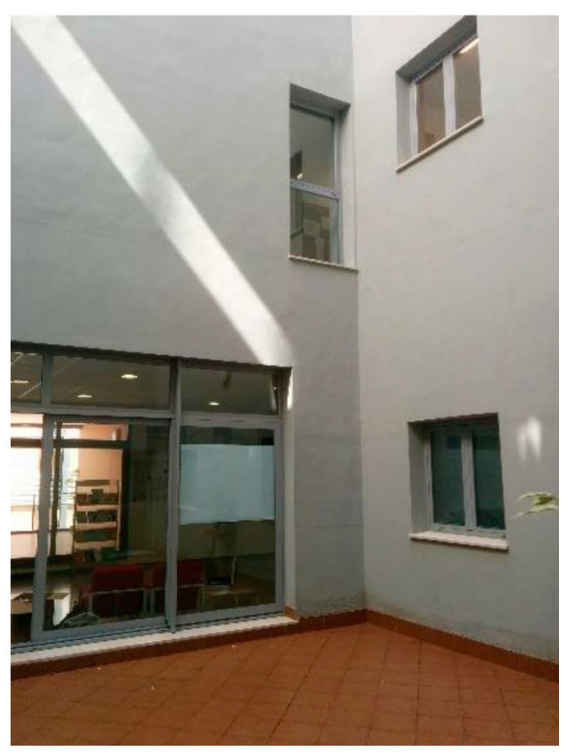

b.

Figure 2. Images of the building. a. View. b. Courtyard.
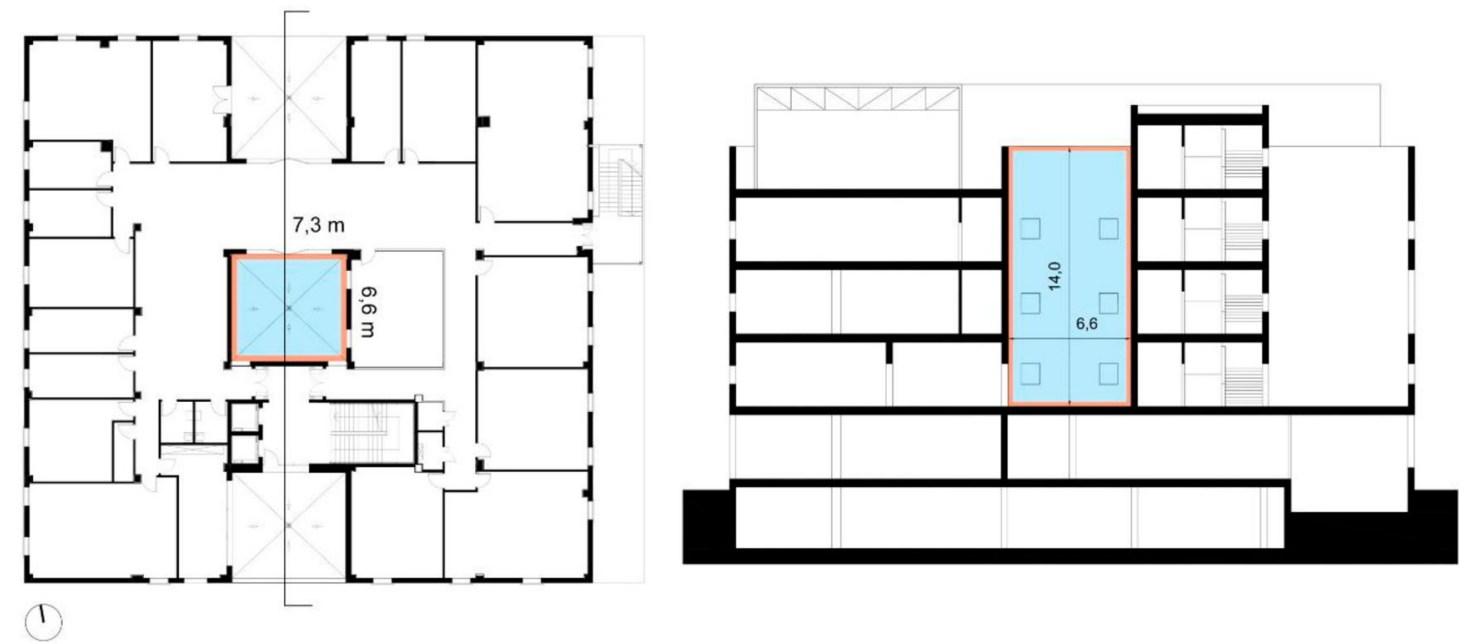

Figure 3. Courtyard drawings.

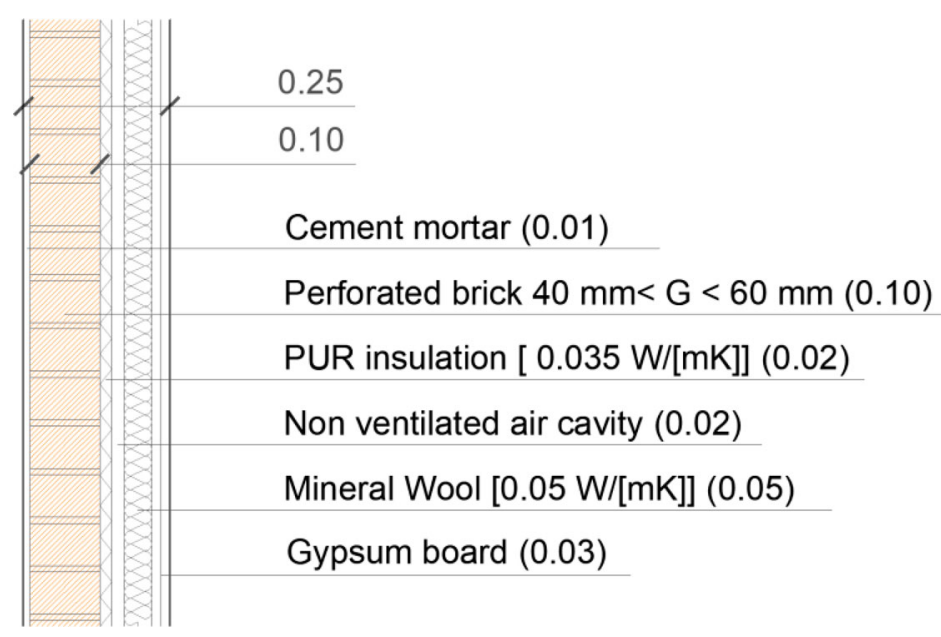

Figure 4. Construction section of the wall. Units in metres. 
Table 1. Wall properties.

\begin{tabular}{lll}
\hline Wall thickness $(\mathrm{m})$ & Brick thermal Conductivity $(\mathrm{W} /(\mathrm{mK}))$ & Emissivity \\
0.10 & 0.67 & 0.93 \\
\hline Specific heat $(\mathrm{Ws} /(\mathrm{KgK}))$ & Density $\left(\mathrm{kg} / \mathrm{m}^{3}\right)$ & Absorption \\
1000 & 1140 & 0.73 \\
\hline
\end{tabular}

assumed in our simplified courtyard is that the effective thickness of the wall is only the $11.5 \mathrm{~cm}$ brick (highlighted area in Figure 4).

In Table 1 it can be found some data relative to walls, like the effective thick mentioned.

\section{Methodology}

The methodology is divided into four sections. Section 3.1 shows the novel coupled model for courtyard simulation. Section 3.2 details the data collection procedure for model validation. Section 3.3 explains the indicator used for validation. And section 3.4. provides details about the comparison with other existing simulation tools. The methodological workflow and the relationship between the inputs and outputs is illustrated in Figure 5.

Three stages can be seen in the graph. At the input data collection stage, the monitoring campaign is performed to record outdoor temperature, relative humidity and wind speed and direction to be used as inputs for the simulations. At the simulation stage, temperatures inside the courtyard are simulated using the proposed model described in the next section and two other existing tools: ENVI-met and the Ladybug tools. Finally, the results of the three different methodologies for simulating the temperature inside the courtyard are compared to monitoring temperature using statistical parameters in order to evaluate the performance of the proposed model with the reference of two of the most used tools to date.

\subsection{Novel coupled model for the for the temperature simulation of courtyards}

The accurate simulation of the thermal behaviour of the courtyard needs a CFD model considering buoyancy, solar radiation, and external wind velocity. The combination of these three effects generates a genuine 3D behaviour of the airflow within the courtyard, so lower dimensional models are not appropriate. No turbulence modelling is needed, as we are interested in studying thermally stable configurations, in which courtyards are thermally efficient. This is the most common case in practice, in particular for the test cases considered. Summer climate in the Seville area is quite dry, with high temperatures, so no moisture is present during summertime. For this reason, we do not include the moisture as state variable in our model.
The main modelling challenge is the accurate computation of the heat exchange with the surrounding walls, of special importance to evaluate the energy needs of the building. This requires a precise mathematical model for the thermal boundary layer within the courtyard and the thermal behaviour of the courtyard walls. With this purpose, we propose a coupled 2D problem at courtyard walls describing wall surface temperature and inner wall temperature. This model is coupled with the standard 3D Boussinesq model for the inner courtyard aerothermal flow. The length of the mesh corresponding to the numerical simulation is $0.2 \mathrm{~m}$.

\subsection{1. $2 d$ surface temperature model}

To compute the temperature at the walls of the courtyard we consider a system of 2D differential equations. This problem involves three different temperatures: the wall surface temperature $\left(\theta_{w}\right)$, the wall inner temperature $\left(\theta_{\text {in }}\right)$ and the courtyard temperature $(\theta)$. Actually, the relevant value of $\theta$ in this model is the temperature at the top of the thermal boundary layer in the air flow within the courtyard. The problem is then solved using the followings equations, that hold on the walls $\Gamma$ of the courtyard:

$$
\begin{aligned}
& \int \boldsymbol{C}_{\boldsymbol{w}} \frac{\partial \boldsymbol{\theta}_{\boldsymbol{w}}}{\partial \boldsymbol{t}}(\boldsymbol{x}, \boldsymbol{t}) \\
& =U_{\text {ext }} A\left(\theta(x \circ \delta, t)-\theta_{w}(x, t)\right) \\
& +\boldsymbol{U}_{\text {in }} \boldsymbol{A}\left(\boldsymbol{\theta}_{\text {in }}(x, t)-\theta_{w}(x, t)\right) \quad x \in \Gamma, t \in[0, T], \\
& +\varepsilon_{w} \sigma A\left(\theta^{4}(x \circ \delta, t)-\theta_{w}^{4}(x, t)\right) \text {, } \\
& +\alpha_{w} A l(x, t)+Q(x, t), \\
& \boldsymbol{C}_{\boldsymbol{w}} \frac{\partial \boldsymbol{\theta}_{\text {in }}}{\partial \boldsymbol{t}}(\boldsymbol{x}, \boldsymbol{t}) \\
& =U_{\text {int }}\left(\theta_{\text {in }}(x, t)-\theta_{w}(x, t)\right), \\
& \boldsymbol{x} \in \boldsymbol{\Gamma}, \boldsymbol{t} \in[0, \boldsymbol{T}],
\end{aligned}
$$

where $\boldsymbol{C}_{\boldsymbol{w}}=\rho_{w} \boldsymbol{c}_{\boldsymbol{w}} \boldsymbol{V}_{\boldsymbol{w}}$ with $\rho_{w}$ the wall density, $\boldsymbol{c}_{\boldsymbol{w}}$ the specific heat of the wall, and $\boldsymbol{V}_{\boldsymbol{w}}$ the wall volume. Also, $\delta$ denotes the thickness of the wall thermal boundary layer within the air flow in the courtyard. Note that $\theta(x \circ \delta, t)$ is the courtyard temperature at the top of the thermal boundary layer. In system (1), $\boldsymbol{U}_{\text {ext }}$ is the transmittance coefficient of the air $\left(25 \mathrm{~W} / \mathrm{m}^{2} \mathrm{~K}\right), \boldsymbol{A}$ is the area of the considered wall, $\boldsymbol{U}_{\text {in }}$ is the transmittance coefficient of the wall (ratio between the heat conductivity and the efficient thickness), $\varepsilon$ is the emissivity, $\sigma$ is the Stefan-Boltzmann constant $\left(5.57 \mathrm{e}-8 \mathrm{~W} /\left(\mathrm{m}^{2} \mathrm{~K}^{4}\right)\right), \boldsymbol{\alpha}_{w}$ is the absorption coefficient, $\boldsymbol{l}$ is the solar radiation and $\mathrm{Q}$ is a net heating radiation transfer simplification. In particular, it is only taken into account the sky temperature transmitted as a long wave being

$$
Q=\mu \varepsilon_{W} \sigma A\left(\theta_{s}(x, t)-\theta_{w}(x, t)\right),
$$




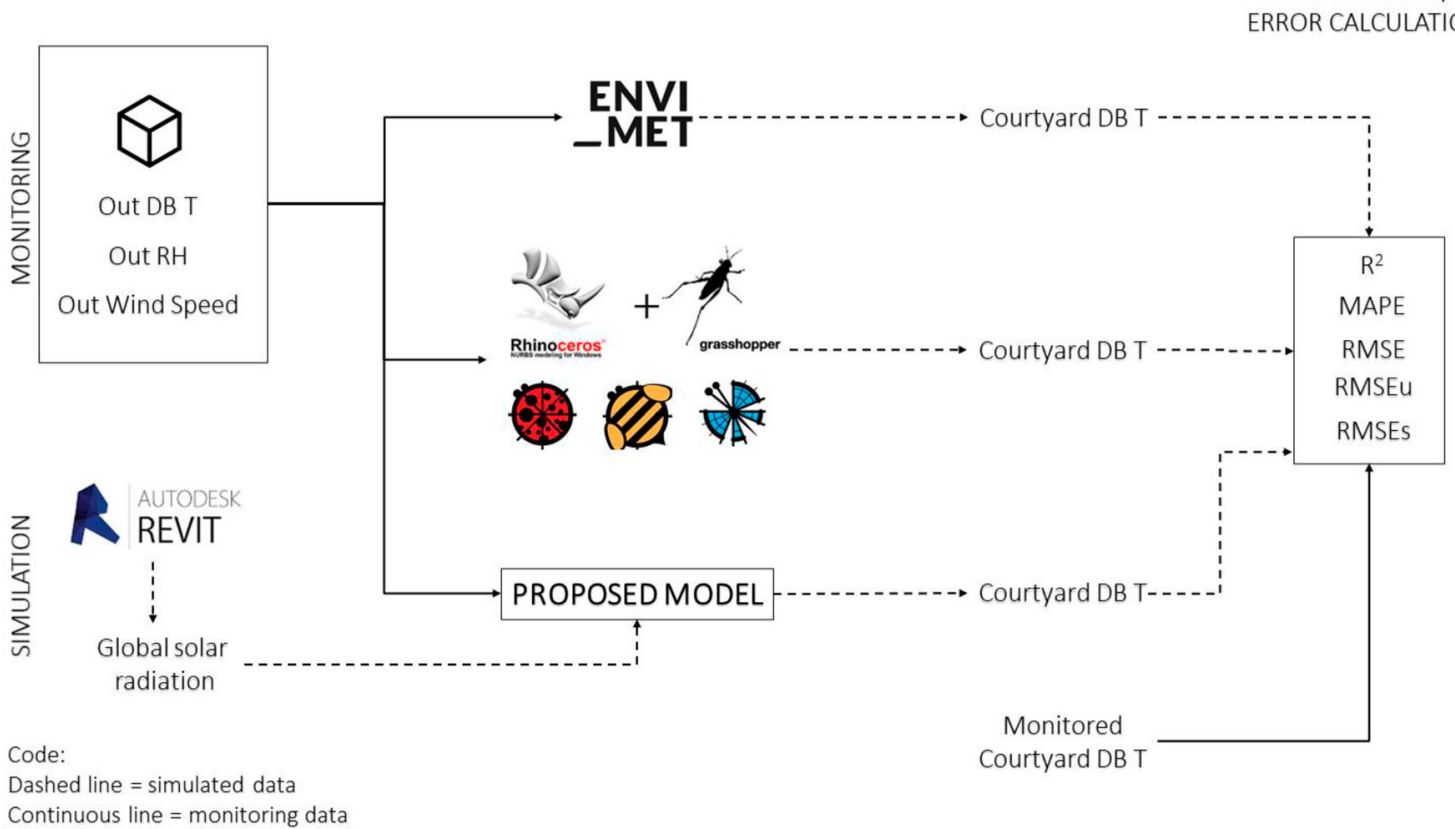

Figure 5. Methodology flowchart showing the inputs and outputs of the numerical model.

where $\boldsymbol{\theta}_{\boldsymbol{s}}$ is the sky temperature and $\mu$ a characteristic function that is zero during the day and one for the night, that is, we consider only the main net heating radiation in the period when there is no solar radiation.

In system (1), the first equation represents the heat balance at the wall surface, while the second one represents the heat balance within the wall. In the first balance, we include diffusive and convective heat transfers across the thermal boundary layer and within the wall, as well as radiation from the courtyard, solar radiation and wall absorption. In the second one we just consider diffusive heat flow between the inner wall and its surface. In both equations the diffusive heat flows are modelled by Newton's law.

Using Newton's law to model diffusive and (especially) convective heat transfer introduces a certain modelling error. However, the alternative would be a fine resolution of the thermal boundary layer, as well as the resolution of the heat equation within the wall. This would need extremely expensive computations.

We consider the non-dimensional version of the systems to reduce the number of parameters appearing in the model, and reducing computing errors. To do so, we assume the followings change of variables:

$$
\begin{aligned}
& x^{*}=\frac{x}{L}, \quad u^{*}=\frac{u L}{\kappa}, \quad t^{*}=\frac{t \kappa}{L^{2}}, \quad p^{*}=\frac{p L^{2}}{\kappa^{2}} \\
& \theta^{*}=\frac{\theta}{\beta}, \quad \theta_{\text {ref }}^{*}=\frac{\theta_{\text {ref }}}{\beta}, \quad I^{*}=\frac{I}{V_{\text {ext }} \theta_{\text {ref }}}
\end{aligned}
$$

where $L$ is a characteristic length of the domain, $\kappa$ is the thermal diffusivity, $\boldsymbol{\beta}$ is a characteristic difference of temperatures, $\boldsymbol{\theta}_{\text {ref }}$ is a characteristic temperature, and $V_{\text {ext }}$ is a characteristic velocity within the courtyard.

The corresponding non-dimensional system reads as follows:

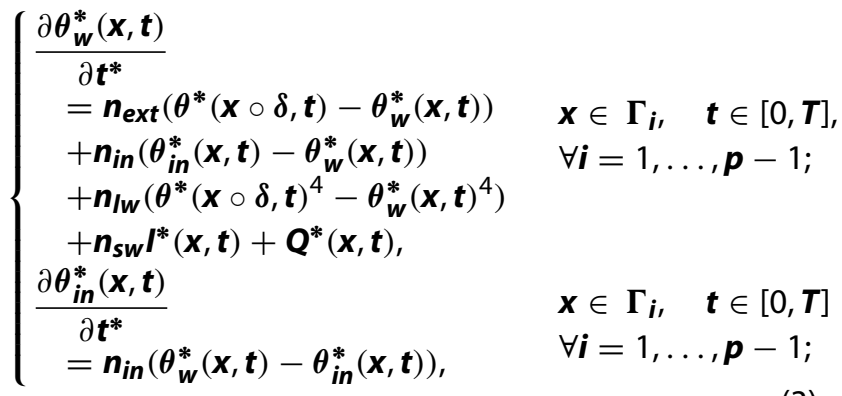

here

$$
\begin{aligned}
& n_{\text {ext }}=\frac{U_{\text {ext }} L^{2}}{\rho_{w} c_{w} e \kappa}, \quad n_{\text {in }}=\frac{U_{\text {in }} L^{2}}{\rho_{w} c_{w} e \kappa}, \quad n_{l w}=\frac{\varepsilon \sigma \beta^{3} L^{2}}{\rho_{w} c_{w} e \kappa}, \\
& n_{\text {sw }}=\frac{\alpha U_{\text {ext }} \theta_{\text {ref }} L^{2}}{\rho_{w} c_{w} e \beta \kappa},
\end{aligned}
$$

where $e$ is the wall thickness. For the numerical simulations we consider $\kappa=2.26 \mathrm{e}-5 \mathrm{~m}^{2} / \mathrm{s}, \mathrm{L}=0.2 \mathrm{~m}$, and $\beta=10^{\circ} \mathrm{C}$.

\subsection{2. $3 d$ courtyard outdoor temperature model}

The temperature inside the courtyard is simulated using a Boussinesq model. Let us denote by $\Omega$ the domain and by $[0, T]$ the time interval, with $T$ the final time. The coupling of the Navier-Stokes equations with variable 
density, depending on the temperature, with the Boussinesq approximation is considered. The unknows of the equations are the air velocity field $(u)$, the temperature inside the courtyard $(\boldsymbol{\theta})$ and the pressure $(\boldsymbol{p})$, satisfying (Bermúdez 2005):

$$
\left\{\begin{array}{l}
\frac{\partial \boldsymbol{u}(\boldsymbol{x}, \boldsymbol{t})}{\partial \boldsymbol{t}}+\boldsymbol{u}(\boldsymbol{x}, \boldsymbol{t}) \cdot \nabla \boldsymbol{u}(\boldsymbol{x}, \boldsymbol{t})-\boldsymbol{v} \boldsymbol{\Delta} \boldsymbol{u}(\boldsymbol{x}, \boldsymbol{t}) \\
\quad+\nabla \boldsymbol{p}(\boldsymbol{x}, \boldsymbol{t})=\boldsymbol{f}(\boldsymbol{x}, \boldsymbol{t}), \boldsymbol{x} \in \boldsymbol{\Omega}, \boldsymbol{t} \in[0, \boldsymbol{T}], \nabla \cdot \boldsymbol{u}=0, \\
\frac{\partial \boldsymbol{\theta}(\boldsymbol{x}, \boldsymbol{t})}{\partial \boldsymbol{t}}+\boldsymbol{u}(\boldsymbol{x}, \boldsymbol{t}) \cdot \nabla \boldsymbol{\theta}(\boldsymbol{x}, \boldsymbol{t})-\boldsymbol{\kappa} \boldsymbol{\Delta} \boldsymbol{\theta}(\boldsymbol{x}, \boldsymbol{t})=0,
\end{array}\right.
$$

where

$$
\boldsymbol{f}=\left(\begin{array}{c}
0 \\
0 \\
\frac{-g \rho}{\rho_{0}},
\end{array}\right) \text { with } \frac{\rho}{\rho_{0}}=1-I_{\alpha}\left(\theta(x, t)-\theta_{\text {ref }}\right)
$$

In the system defined by (5) and (6), we denote by $v$ the kinematic viscosity, $\rho$ the density, $\boldsymbol{I}_{\alpha}$ the thermal expansion coefficient $\left(3.43 \mathrm{e}-3^{\circ} \mathrm{C}^{-1}\right), \boldsymbol{\theta}_{\text {ref }}$ a reference temperature, $\boldsymbol{\kappa}$ the thermal diffusion, $\boldsymbol{g}$ the gravity constant $\left(9.81 \mathrm{~m} / \mathrm{s}^{2}\right)$ and $\rho_{0}$ a reference air density $\left(1.19 \mathrm{~kg} / \mathrm{m}^{3}\right)$.

To describe the boundary conditions, let us consider that the boundary of the domain $\boldsymbol{\Omega}$ is divided into $\boldsymbol{p}$ boundaries $\Gamma_{\boldsymbol{i}}$, for $\boldsymbol{i}=1, \ldots, \boldsymbol{p}$. We will assume that $\Gamma_{i}$ $\forall i=1, \ldots, p-2$ are the lateral surfaces of the courtyard, $\Gamma_{p-1}$ is the ground floor and $\Gamma_{p}$ is a fictitious roof of the courtyard, which is opened to the sky.

For $\theta$ we consider Dirichlet conditions for $\boldsymbol{i}=1, \ldots$, $\boldsymbol{p}-1$, and Neumann condition for the last one, $\boldsymbol{\Gamma}_{\boldsymbol{p}}$. Dirichlet conditions are considered in all boundaries for $\boldsymbol{u}$.

Then, boundary conditions are defined as follows:

$$
\left\{\begin{array}{llc}
u(x, t)=0, & x \in \Gamma_{i}, \quad i=1, \ldots, p-1, \\
u(x, t)=u_{s,} & x \in \Gamma_{p}, \quad \\
\theta(x, t)=\theta_{w}(x, t), & x \in \Gamma_{i}, \quad i=1, \ldots, p-1, \\
\frac{\partial \theta_{w}}{\partial n}=0, & x \in \Gamma_{p},
\end{array}\right.
$$

while the initial conditions are

$$
\theta(x, 0)=\theta_{\text {op }}, \quad u(x, 0)=u_{\text {op }} \quad x \in \boldsymbol{\Omega},
$$

where $\boldsymbol{n}$ in the system (7) is the outer normal to $\boldsymbol{\Gamma}_{\boldsymbol{p}}$, and $\boldsymbol{\theta}_{\boldsymbol{o p}}, \boldsymbol{u}_{\boldsymbol{o p}}$ in (8) are the initial temperature and velocity inside the courtyard, respectively.
By applying the previous changes of variables, we obtain the following non-dimensional model:

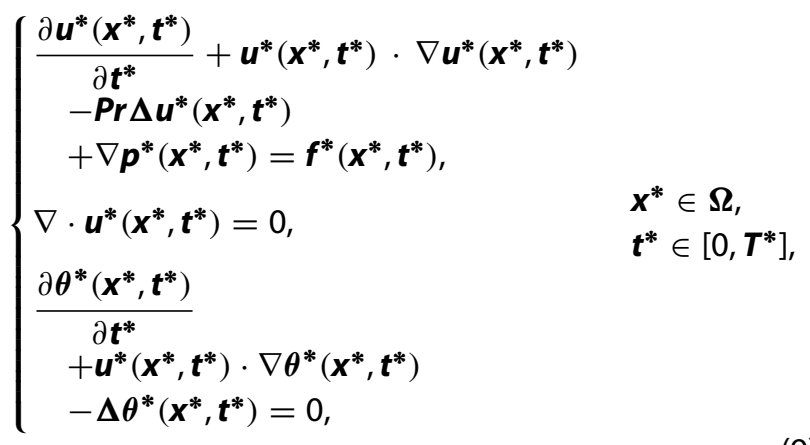

with

$$
\boldsymbol{f}^{*}=\left(\begin{array}{c}
0 \\
0 \\
\operatorname{Ra} \operatorname{Pr}\left(\theta^{*}(\boldsymbol{x}, \boldsymbol{t})-\theta_{\text {ref }}^{*}\right)
\end{array}\right)
$$

where $\operatorname{Pr}$ and $R a$ are the dimensionless Prandtl and Rayleigh numbers, given by

$$
\operatorname{Pr}=\frac{v}{\kappa}, \quad R a=\frac{g \alpha \beta L^{3}}{\kappa v}
$$

The non-dimensional boundary conditions are:

$$
\begin{cases}\boldsymbol{u}^{*}\left(\boldsymbol{x}^{*}, \boldsymbol{t}^{*}\right)=0, & \boldsymbol{x}^{*} \in \boldsymbol{\Gamma}_{\boldsymbol{i}}, \quad \boldsymbol{i}=1, \ldots, \boldsymbol{p}-1, \\ \boldsymbol{u}^{*}\left(\boldsymbol{x}^{*}, \boldsymbol{t}^{*}\right)=\boldsymbol{u}_{\boldsymbol{s}}^{*}, & \boldsymbol{x}^{*} \in \boldsymbol{\Gamma}_{\boldsymbol{p}}, \\ \boldsymbol{\theta}^{*}\left(\boldsymbol{x}^{*}, \boldsymbol{t}^{*}\right)=\boldsymbol{\theta}_{w}^{*}\left(\boldsymbol{x}^{*}, \boldsymbol{t}^{*}\right), & \boldsymbol{x}^{*} \in \boldsymbol{\Gamma}_{\boldsymbol{i}}, \quad \boldsymbol{i}=1, \ldots, p-1, \\ \frac{\partial \boldsymbol{\theta}_{w}^{*}}{\partial \boldsymbol{n}}=0, & \boldsymbol{x}^{*} \in \boldsymbol{\Gamma}_{\boldsymbol{p}},\end{cases}
$$

Let us recall that the Prandtl number is the ratio between the kinematic viscosity and the thermal diffusion. The Rayleigh number is associated with the heat transfer in the fluid and measures the ratio between buoyancy and viscous forces. When the Rayleigh number is below a critical value $\left(R a_{c r}=10^{5}\right)$, heat transfer is primarily in the form of conduction, but when it exceeds this critical value, heat transfer is primarily in the form of convection (Benítez and Bermúdez 2011; Chacón Rebollo et al. 2018). Moreover, in the last case, if the Rayleigh number exceeds a certain threshold $\left(R a_{t h}=10^{8}\right)$ the flow is unstable (Rabinowitz 1968). This instability is called RayleighBénard instability (Schlichting and Gertesten 2004).

\subsubsection{Coupled model}

We consider finally a model that couples the 3D courtyard outdoor model and the 2D system that describes the temperature evolution on the walls in a non-dimensional form (13). In what follows, we omit the asterisk marks in the definition of the non-dimensional coupled model. 
The coupled model is the following one:

$$
\begin{aligned}
& \frac{\partial \boldsymbol{u}(\boldsymbol{x}, \boldsymbol{t})}{\partial \boldsymbol{t}}+\boldsymbol{u}(\boldsymbol{x}, \boldsymbol{t}) \cdot \nabla \boldsymbol{u}(\boldsymbol{x}, \boldsymbol{t}) \\
& -\operatorname{Pr} \Delta u(x, t) \\
& +\nabla p(x, t)=f(x, t) \\
& \nabla \cdot \boldsymbol{u}(\boldsymbol{x}, \boldsymbol{t})=0, \\
& u(x, t)=0 \\
& u(x, t)=u_{s} \\
& \frac{\partial \theta(\boldsymbol{x}, \boldsymbol{t})}{\partial \boldsymbol{t}}+\boldsymbol{u}(\boldsymbol{x}, \boldsymbol{t}) \cdot \nabla \theta(\boldsymbol{x}, \boldsymbol{t}) \\
& -\Delta \theta(x, t)=0 \\
& \theta(x, t)=\theta_{w, i}(x, t) \\
& \frac{\partial \boldsymbol{\theta}}{\partial \boldsymbol{n}}=0 \\
& \frac{\partial \boldsymbol{\theta}_{\boldsymbol{w}, \boldsymbol{i}}(\boldsymbol{x}, \boldsymbol{t})}{\partial \boldsymbol{t}} \\
& =\boldsymbol{n}_{\text {ext }}\left(\theta(x \circ \delta, t)-\theta_{w, i}(x, t)\right) \\
& +n_{\text {in }}\left(\theta_{i n, i}(x, t)-\theta_{w, i}(x, t)\right) \\
& +\boldsymbol{n}_{\text {Iw }}\left(\left(\boldsymbol{\theta}(\boldsymbol{x} \circ \boldsymbol{\delta}, \boldsymbol{t})+\frac{1}{\beta} \theta_{\text {ref }}\right)^{4} \quad \text { on } \boldsymbol{\Gamma}_{\boldsymbol{i}} \times[0, \boldsymbol{T}]\right. \\
& \left.-\left(\boldsymbol{\theta}_{w, i}(\boldsymbol{x}, \boldsymbol{t})+\frac{1}{\beta} \boldsymbol{\theta}_{\text {ref }}\right)^{4}\right) \\
& +n_{s w} \mathbf{l}+\mathbf{Q} \\
& \begin{array}{l}
\frac{\partial \theta_{i n, i}(x, t)}{\partial \boldsymbol{t}} \\
\quad=\boldsymbol{n}_{\text {in }}\left(\theta_{w, i}(x, t)-\theta_{i n, i}(x, t)\right)
\end{array} \\
& \text { in } \boldsymbol{\Omega} \times[0, T] \text {, } \\
& \text { on } \Gamma_{i} \times[0, T] \\
& \forall \boldsymbol{i}=1, \ldots, \boldsymbol{p}-1 \text {, } \\
& \text { on } \Gamma_{p} \times[0, T] \text {, } \\
& \forall \boldsymbol{i}=1, \ldots, \boldsymbol{p}-1 \\
& \text { on } \Gamma_{i} \times[0, T] \\
& \forall \boldsymbol{i}=1, \ldots, \boldsymbol{p}-1
\end{aligned}
$$

The coupled model has been programmed using FreeFEM open-source software for finite elements (v4.4), which is written in C++ language ("FreeFEM"). The FreeFEM opensource software allows processing numerous types of mathematical codes and numerical methods to work with CFD. Moreover, it allows taking into account in the model the different characteristics of courtyards, like materials, which compose walls, the transmittance of the air and walls, emission and absorption of radiation, solar radiation, courtyard size, outdoor wind velocity, material density, specific heat, and volume. We have considered physical parameters for the air, so that $\operatorname{Pr}=0.71$, and for the selected case study $R a$ approximately $10^{7}$. Since we are in a convection-dominated regime, we have used the method of characteristics (Benítez and Bermúdez 2011) in order to avoid spurious instabilities (Gresho et al. 1980).

The developed code allows reproducing and carrying out graphic representations of a courtyard thermal behaviour in relation to the characteristics mentioned before. In short, simulations using the proposed FreeFEM code make it possible to accurately predict the temporal evolution of the temperature inside a courtyard.

\subsection{Data collection for validation procedure}

The monitoring campaign of atmospheric data has been extended throughout a whole year; therefore, there are winter and summer data available. The recorded parameters are air temperature, wind direction, and speed of the outdoor of the courtyard, measured by a meteorological station model PCE- FWS 20 located on the roof of the building (Figure 6.a). This information is used as input data for the simulation. Inside the courtyard, air temperature and relative humidity have been recorded using sensors model TESTO 174H, located in the south façade of the courtyard to avoid direct solar radiation, at 1, 2, 5, and $8 \mathrm{~m}$, from the floor (Figure 6.b and c). The devices are also protected by a reflective shield to prevent overheating from solar radiation if it happens. These data are used to validate the results provided by the proposed numerical model.

Table 2 shows the technical specification of the instruments used.

The global solar radiation in the walls of the courtyard is another parameter that is needed as input to the simulation of the proposed model. These values have been extracted using the software REVIT Solar Analysis, given the difficulties of having monitoring data, to provide accurate data in the vertical surfaces of the walls. This software uses weather data provided by Green Building Studio and has industry-leading testing and validation standards ("Help: Weather Data in GBS" 2020; "Help: Green Building Studio Validation" 2020). Clear sky days have been selected to simulate in order to avoid errors due to cloudiness, not considered by the software. (See Appendix $B$ for detailed information about radiation)

\subsection{Simulation performance indicators.}

In order to compare the simulation performance of each model, monitored and simulation data are compared. The comparison is performed spatially and temporally. The temperature inside the courtyard at 2,5 , and $8 \mathrm{~m}$ is selected as an indicator to evaluate the simulation performance of the models. Two days have been selected to be simulated: the 2 nd of August of 2018 and the $6^{\text {th }}$ of October of 2017, both with high temperatures and clear skies, but at a different time of the year, meaning differences in the solar radiation that reaches the walls. The two days' period selected means a total time of $48 \mathrm{~h}$ of simulation. This is considered enough to evaluate the model performance based on previous outdoor CFD studies, that 


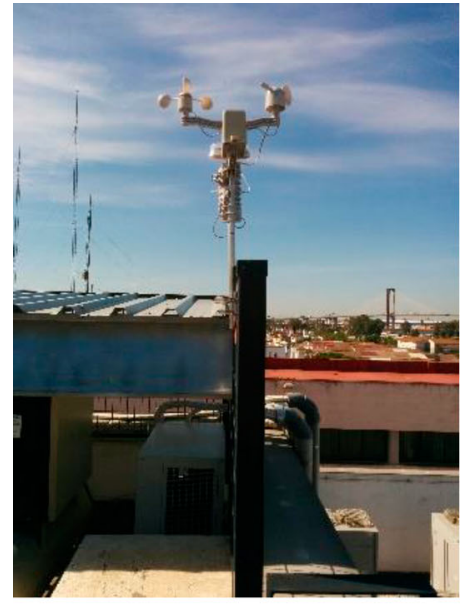

a.

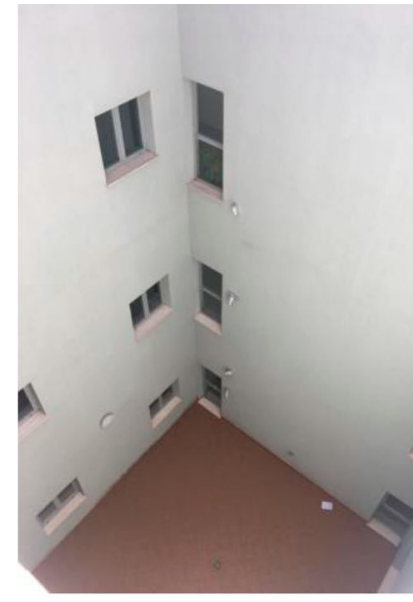

b.

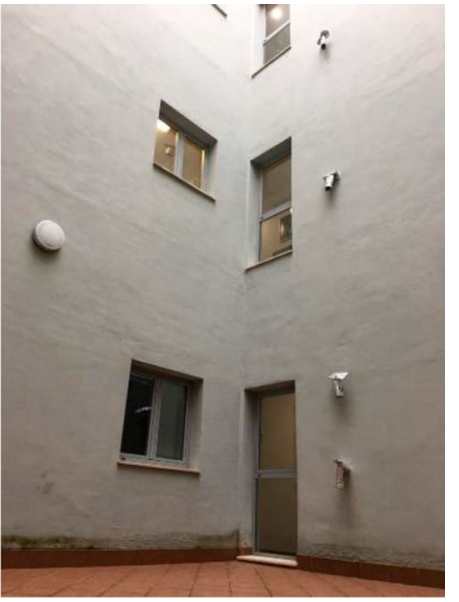

C.

Figure 6. Images of the measuring instruments placed at the case study. a. Weather Station at the roof. b. Temperature and relative humidity sensors. Top view. c. Temperature and relative humidity sensors. Bottom view.

Table 2. Measured variables, technical data of the instruments and observation parameters.

\begin{tabular}{llllccc}
\hline Situation & Sensor & Variable & Accuracy & Range & Resolution & Interval \\
\hline Courtyard & TESTO 174H & $\mathrm{Ta}^{\mathrm{a}}$ & $\pm 0.5^{\circ} \mathrm{C}$ & $-20 \mathrm{a}+70^{\circ} \mathrm{C}$ & $0.1^{\circ} \mathrm{C}$ & $15 \mathrm{~min}$ \\
& & $\mathrm{RH}$ & $\pm 0.1 \%$ & $0 \mathrm{a} 100 \%$ & $2 \%$ & $15 \mathrm{~min}$ \\
Outdoor & $\mathrm{PCE}-$ FWS 20 & $\mathrm{Ta}^{\mathrm{a}}$ & $\pm 1{ }^{\circ} \mathrm{C}$ & $-40 \mathrm{a}+65^{\circ} \mathrm{C}$ & $0.1^{\circ} \mathrm{C}$ & $20 \mathrm{~min}$ \\
& & $\mathrm{RH}$ & $\pm 5 \%$ & $12 \mathrm{a} 99 \%$ & $1 \%$ & $20 \mathrm{~min}$ \\
& & Wind Speed & $\pm 1 \mathrm{~m} / \mathrm{s}$ & $0 \mathrm{a} 180 \mathrm{~km} / \mathrm{h}$ & - & $20 \mathrm{~min}$ \\
\hline
\end{tabular}

varies from one day (Forouzandeh 2018; Nasrollahi et al. 2017; Salata et al. 2016) to a few days (Acero and HerranzPascual 2015; Antoniou et al. 2019) and looking for a balance between computational resources and accuracy of the results.

There is a reference standard to validate indoor energy consumption, the ASHRAE Guideline 14-2014 (ASHRAE 2014), which does not apply to outdoor simulation, but it will be taken as a reference to use the same statistical indexes and validation values. These indices are the Normalized Mean Bias Error (NMBE), which should be less than $10 \%$, the Coefficient of Variation of the Root Mean Square Error (CV-RMSE) that should be less than $30 \%$ and the Coefficient of determination $\left(R^{2}\right)$, higher than 0.75 . The Root Mean Square Error (RMSE) is also include given it is widely used and it gives a quantitative result (it should be close to 0 ). The equations for these parameters are displayed in Appendix C.

\subsection{Comparison with existing simulation tools: ENVI-met and Ladybug tools}

\subsubsection{ENVI-met simulation}

ENVI-met is the commercial software that has been selected to compare the results of our algorithm because it is widely used and validated by the researchers for the simulation of urban microclimates. This software allows the simulation of microclimates applying the fundamental laws of fluids and thermodynamics, including interactions between buildings, vegetation, soil, and air. Its resolution allows the simulation of interactions on a small scale as the ones that happen in courtyards in our case study.

The model geometry and characteristics are summarized in Tables 3 and 4. The hourly outdoor temperature, relative humidity and mean wind speed and direction from monitored data for each day is used as boundary conditions for the simulation. These data are displayed in tables in Appendix A. The 2-equation Turbulence Kinetic Energy (TKE) Model is used by the software to predict the turbulence in the air. ENVI-met needs initialization time to provide accurate data, that is why the simulation has been carried out during $36 \mathrm{~h}$, starting in the previous day, and only the last $24 \mathrm{~h}$ have been taken as outputs, taking an average time from the recommendation of other authors (Forouzandeh 2018; Salata et al. 2016). To ensure the highest accuracy in the software, different simulations have been performed changing the size of the model and nesting grids and following the same methodology of previously simulated courtyards (López-Cabeza et al. 2018). We also consider a balance between accuracy and simulation time.

\subsubsection{Ladybug tools simulation}

The Ladybug Tools are a set of plugins for Grasshopper that support environmental design ("Ladybug Tools | 
Table 3. Description of the model geometry for ENVI-met simulation.

\begin{tabular}{ll}
\hline Number of grid cells & \multicolumn{1}{c}{$85 \times 85 \times 30$} \\
\hline Size of the cells $(\mathrm{m})$ & $1 \times 1 \times 1$ \\
$(\mathrm{x}, \mathrm{y}, \mathrm{z})$ & Telescoping factor $12 \%$. Start at $18 \mathrm{~m}$ \\
& height. \\
Nesting grids & 4 \\
Model rotation out of grid north & 0 \\
& $\mathrm{n}-\mathrm{s}$ \\
\hline
\end{tabular}

Table 4. Major input variables for ENVI-met.

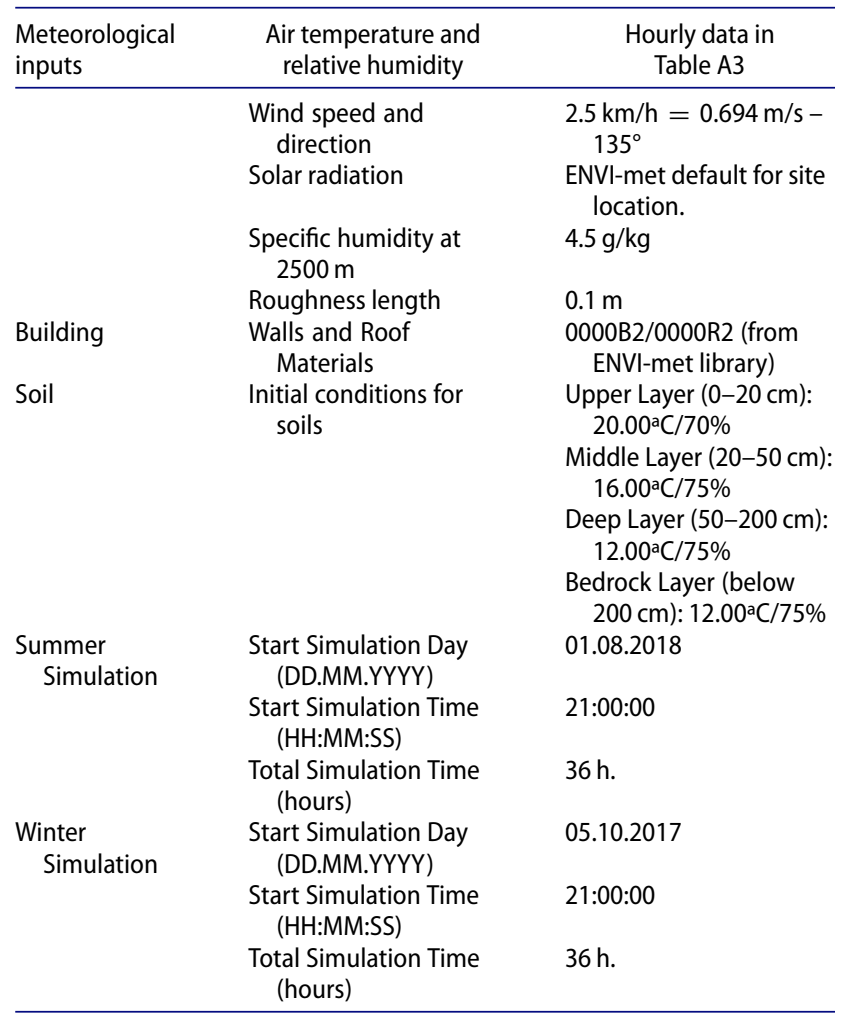

Home Page" 2020). They connect the 3D Computer-Aided Design (CAD) interfaces to a host of validated simulation engines such as Radiance, EnergyPlus, Therm, and OpenFOAM. This last one allows the use of CFD simulations; thus, this software is selected to compare the results with the model proposed.

The building geometry is defined in the Rhinoceros interface. The simulation domain is a $250 \times 500 \times 50 \mathrm{~m}$ box simulating a wind tunnel. The mesh definition is performed using the OpenFOAM's blockMesh utility for the whole domain and the snappyHexMesh to snap the mesh to the building geometry. It has four levels of refinement around the case study, with a total of 982,437 cells.

The buoyantBoussinesqSimpleFoam solver is selected. This is a steady-state solver for buoyant, turbulent flow of incompressible fluids that uses the Boussinesq approximation. The RNG k-epsilon turbulence model is used. Some other parameters for the simulations are shown
Table 5. OpenFOAM simulation parameters.

\begin{tabular}{ll}
\hline Parameter & \multicolumn{1}{c}{ Value } \\
\hline Air temperature & Hourly data in Table A3 \\
Relative humidity & Hourly data in Table A3 \\
Wind speed and direction & $3 \mathrm{Km} / \mathrm{h}$ from west. \\
Building surface temperature & Outputs from EnergyPlus simulation \\
Turbulence model & RNG k-epsilon \\
Turbulent kinetic energy & $0.1 \mathrm{~m} 2 / \mathrm{s} 2$ \\
Turbulence dissipation rate & $0.1 \mathrm{~m} 2 / \mathrm{s} 3$ \\
Reference Temperature & $33^{\circ} \mathrm{C}$ \\
BlockMesh cells & $250 \times 100 \times 20$ \\
Refinement levels & 4 \\
\hline
\end{tabular}

Table 6. OpenFOAM boundary conditions (types).

\begin{tabular}{llll}
\hline & Buildings and Box Boundaries & \multicolumn{1}{c}{ Outlet } & \multicolumn{1}{c}{ Inlet } \\
\hline alpha & alphatJayatillekeWallFunction & zeroGradient & zeroGradient \\
epsilon & epsilonWallFunction & inletOutlet & fixedValue \\
k & kqRWallFunction & inletOutlet & fixedValue \\
nut & nutkWallFunction & calculated & calculated \\
$P \_r g h$ & fixedFluxPressure & fixedValue & zeroGradient \\
T & fixedValue & zeroGradient & fixedValue \\
U & fixedValue & inletOutlet & fixedValue \\
\hline
\end{tabular}

Table 7. EnergyPlus energy simulation parameters.

\begin{tabular}{ll}
\hline Parameter & \multicolumn{1}{c}{ Value } \\
\hline Conditioned & Yes \\
Zone loads: Lighting & $10 \mathrm{~W} / \mathrm{m}^{2}$ \\
Occupancy & 0.05 People $/ \mathrm{m}^{2}$ \\
Equipment & $6.88 \mathrm{~W} / \mathrm{m}^{2}$ \\
Schedule & EnergyPlus Office Schedules \\
Material prop.: Walls & $\mathrm{U}=0.45 \mathrm{~W} / \mathrm{m}^{2} \mathrm{~K}$ \\
Roofs & $\mathrm{U}=0.85 \mathrm{~W} / \mathrm{m}^{2} \mathrm{~K}$ \\
G. Floors & $\mathrm{U}=1.44 \mathrm{~W} / \mathrm{m}^{2} \mathrm{~K}$ \\
Windows & $\mathrm{U}=2.36 \mathrm{~W} / \mathrm{m}^{2} \mathrm{~K}$, SHGC $=0.73$ \\
Infiltration & $0.00022 \mathrm{~m}^{2} / \mathrm{s} \mathrm{m}^{2}$ \\
Ventilation per area & $0.0003 \mathrm{~m}^{3} / \mathrm{s}-\mathrm{m}^{2}$ \\
Ventilation per person & $0.0023 \mathrm{~m}^{3} / \mathrm{s}-$ person \\
Shading & None applied \\
Floor height & $4.0 \mathrm{~m}$ \\
\hline
\end{tabular}

in Table 5, and the boundary conditions for all the elements are described in Table 6. Meteorological conditions from monitoring campaigns are inputs for the wind inlet, and the surface temperatures for the buildings are simulated using the Ladybug tool linked engine EnergyPlus for building energy simulation (energy simulations parameters shown in Table 7)

\section{Results}

\subsection{Results of the novel coupled numerical model}

In this section, we report some numerical tests realized with the mathematical model presented in section 3.1. Two days have been chosen to test the model, October $6^{\text {th }}, 2017$ and August 2nd, 2018, knowing the initial temperature at 9:00, which is the time when outdoor and courtyard temperatures are almost the same. We analyse the temperature evolution compared with experimental 

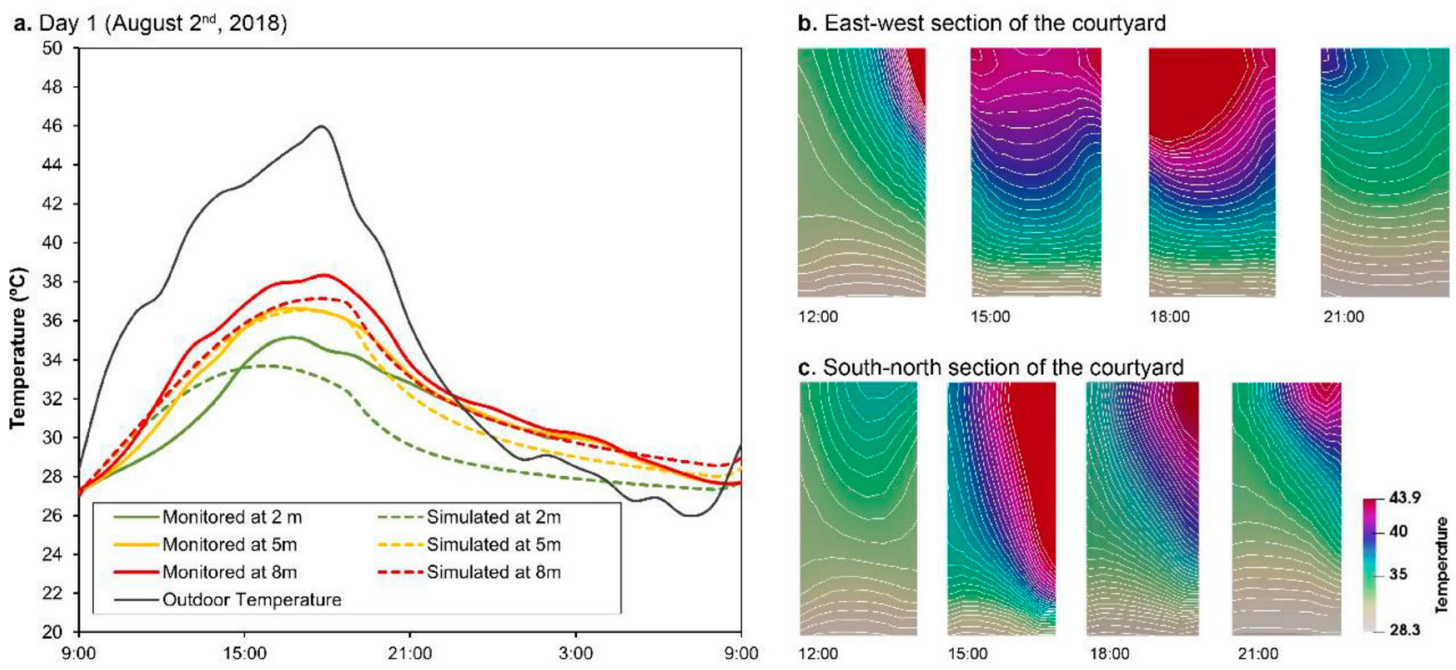

Figure 7. Results from proposed model for Day 1 (August 2nd, 2018). (a). Monitored and simulated temperature. (b) Sections of simulated air temperature in the courtyard.

results and how the radiation and wind velocity influence these results.

A simplified courtyard geometry has been used for the simulations. All walls have the same height, considering the courtyard as a parallelepiped. Furthermore, it is supposed that there are not any elements or windows inside the courtyard.

Previously reported outdoor temperature and radiation in the courtyard are inputs in the simulation. In addition, another information that influences the temperature inside a courtyard is the wind velocity and direction. These values on the top of the courtyard are in Table $\mathrm{A} 1$ and Table $\mathrm{A} 2$ in the appendix. Air velocity inside the courtyard is zero initially. To be able to compare with the monitored data, temperatures were taken at the same position where the sensors were placed in the courtyard.

Using the 3D courtyard outdoor temperature model coupled with the 2D surface temperature model (15) and the data defined, we get the following results for the studied days.

The simulation of August 2nd, 2018 is presented in Figure 7. Its first graph compares simulated and monitored results. It can be seen that simulated results are quite accurate with respect to monitored data. The monitoring data shows that outdoor maximum temperature is above $40^{\circ} \mathrm{C}$ between 13:00 and 18:00 h. However, the microclimate generated in the courtyard reduces the outdoor temperature even in the hottest hours of the day up to $10^{\circ} \mathrm{C}$ at the lowest level. Another interesting effect is the stratification of the temperature: the lowest temperatures are at the lowest levels and they increase with the height. An overheating effect is also detected during the night, when the temperature of the courtyard is higher than the temperature outside.
However, there are some imbalances between the measured and simulated temperature mainly at $2 \mathrm{~m}$. The reason for this could be that the simplified courtyard is considering all walls with the same height and no windows, which may result in some inaccuracies since, with no windows, for instance, the reflection phenomena are not contributing to the warming up of the courtyard, which explains the higher monitored temperatures.

Now, we analyse the temperature evolution inside the courtyard. Figure 7.b and Figure 7.c shows some sections in the middle of the courtyard in both directions. The temperatures of the air present a clear stratification. Another $3 \mathrm{D}$ expected behaviour is properly simulated with the model. As the sun rises from the east, the air becomes warmer near the north and west walls. After some time, as the sun moves to the west, the air becomes warmer in all the upper part of the courtyard, but it is progressively warmer close to the east wall.

Figure 8 represents the courtyard temperatures and air velocity at 18:00 $\mathrm{h}$. The north wall is completely warm, as could be observed in Figure 7. The east wall starts to raise its temperature due to the sun position.

Results from the simulation on October $6^{\text {th }}, 2017$ are presented in Figure 9. The initial conditions for this simulation are the surface temperature $21.2^{\circ} \mathrm{C}$, the temperature inside the courtyard $21^{\circ} \mathrm{C}$, and inner temperature $22.4^{\circ} \mathrm{C}$. The values for radiation for this time of the year are much lower than in summer (see Appendix B). The values of wind direction and speed are shown in Table A2 in the appendix, presenting higher speeds and more direction variability than on August 2 nd, 2018. The maximum monitored outdoor temperature this day is $36.8^{\circ} \mathrm{C}$ at 17:00 h. 

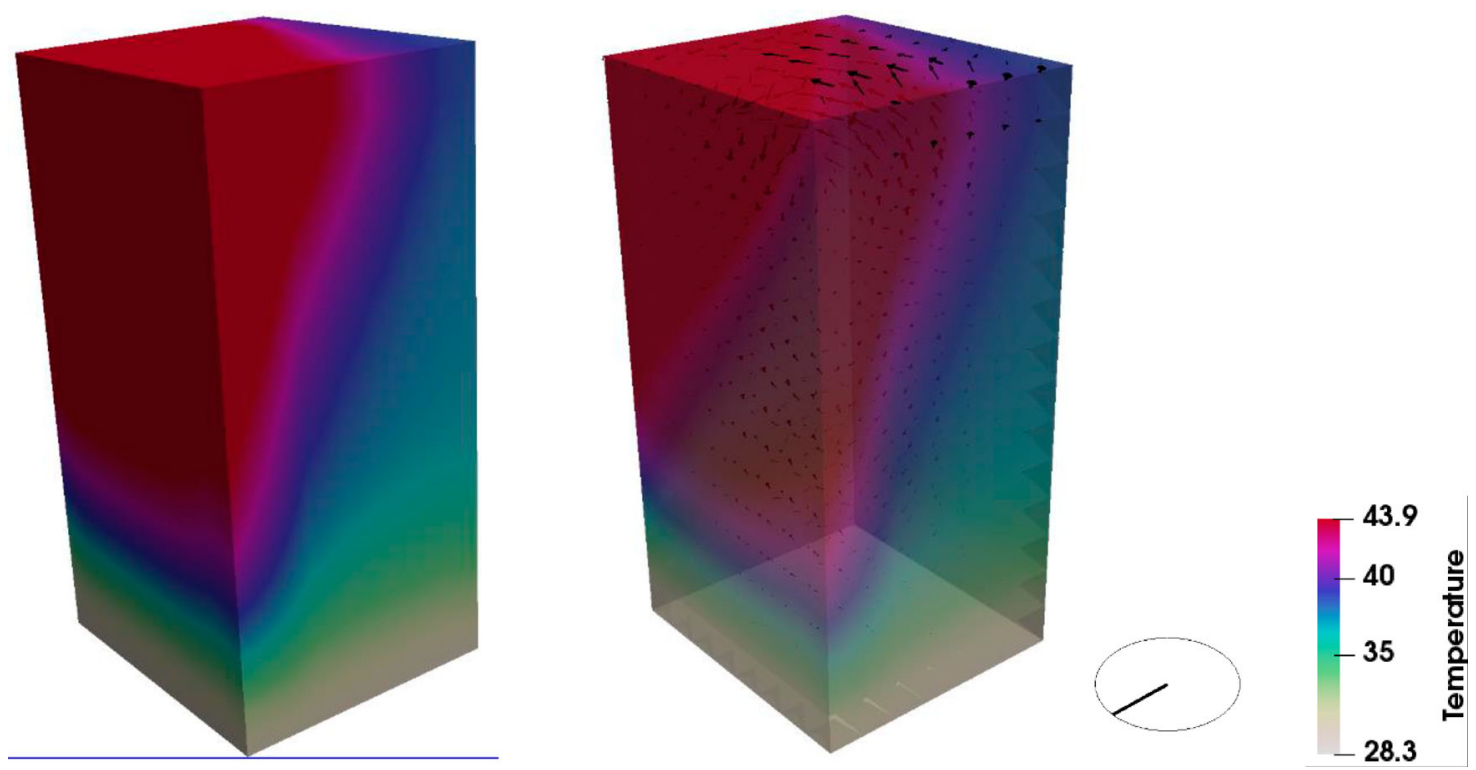

Figure 8. 3D view of the simulated air temperature and air direction (right) in the courtyard for August 2nd, 2018 at 15:00 h.
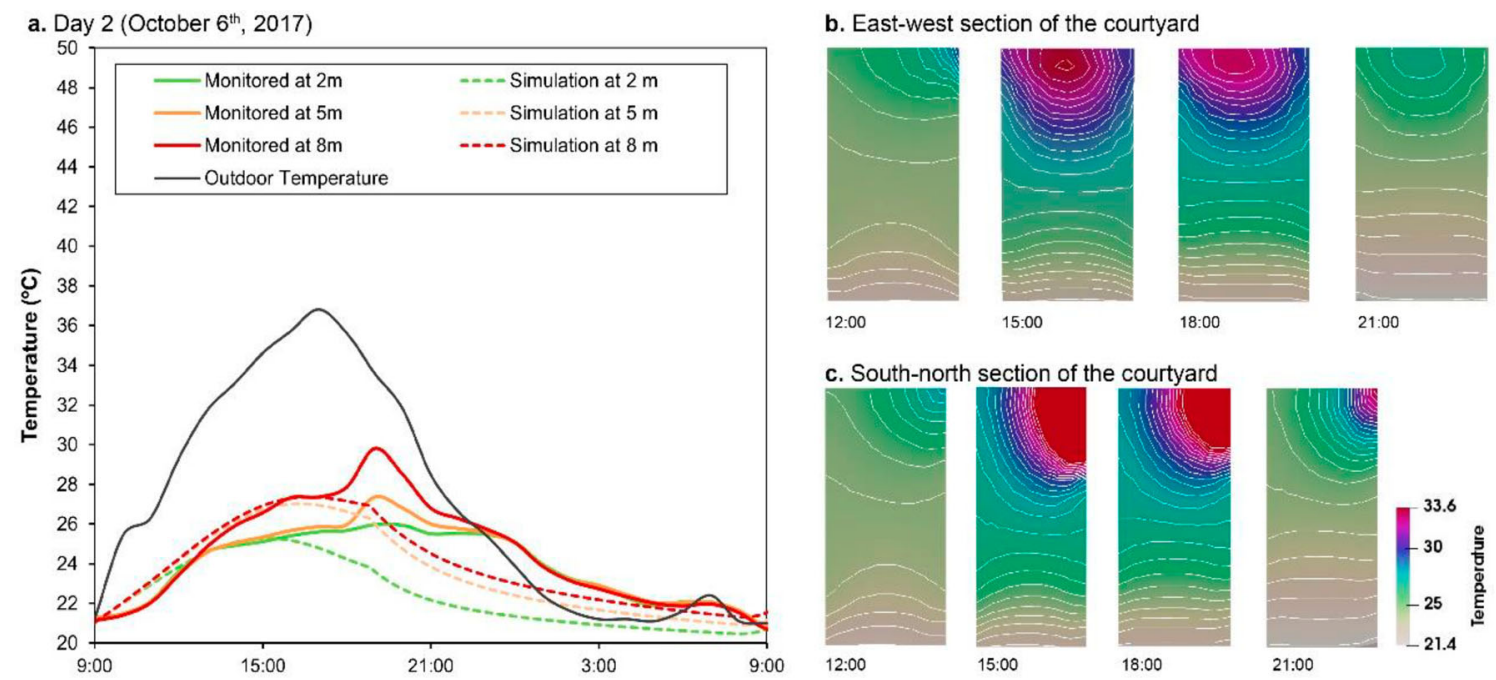

Figure 9. Results from proposed model for Day 2 (October 6th, 2017). (a). Monitored and simulated temperature. (b) Sections of simulated air temperature in the courtyard.

The simulated and measured temperatures are represented in Figure 9.a. It can be seen that there is good accordance with measured temperatures at the beginning of the day, but the simulated tendency starts to decrease earlier than measured temperatures, resulting in a worse accuracy in the afternoon. There is better accuracy at the highest levels, as in the previous simulation.

The faster cooling down of the temperature of the simulation model could be a result of the simplified geometry. Note that the walls of the model courtyard are all of the same height, while one of the walls of the real courtyard is higher than the others. Then the vortex generated by the wind at the upper part of the real courtyard is smaller than the vortex computed for the model courtyard. Moreover, wind speeds of October $6^{\text {th }}, 2017$ are larger than those of August 2nd, 2018. Then, the difference of the sizes between both vortices is larger for the simulation of October $6^{\text {th }}, 2017$. This may explain why the computed temperatures are smaller than the measured ones, and why the difference between the computed and measured temperatures corresponding to October $6^{\text {th }}, 2017$ is larger than the difference corresponding to August 2nd, 2018.

In Figure 9.b and Figure 9.b the evolution of the temperature in the courtyard is represented. East-West and South-North vertical sections in the middle of the courtyard at different hours are represented. The stratification effect is also noticeable, the lower cold air and upper warm air zones are clearly separated. This produces a 


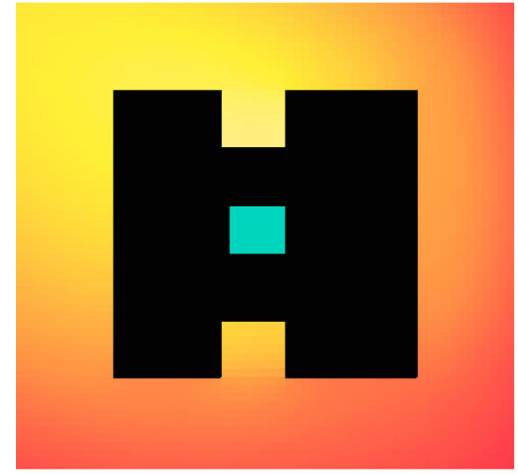

a) Floor plan of the courtyard

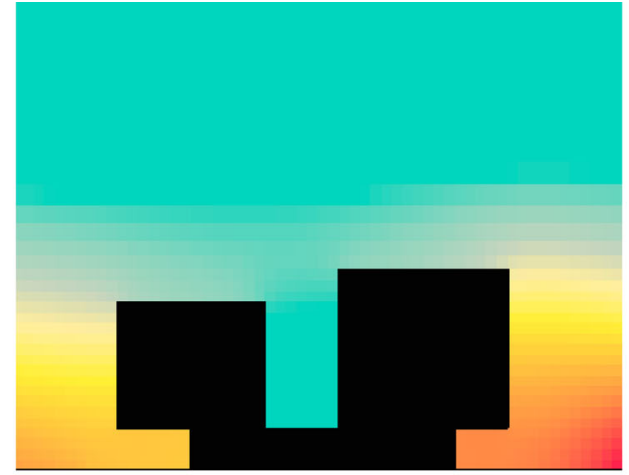

b) South-north section of the courtyard
Potential Air Temperature

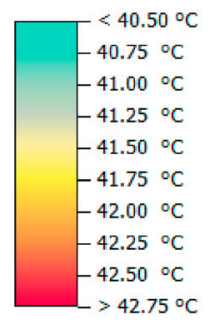

Min: $40.61^{\circ} \mathrm{C}$ Max: $42.98^{\circ} \mathrm{C}$

Figure 10. ENVI-met simulation results on August 2nd, 2018 at $4.00 \mathrm{pm}$.

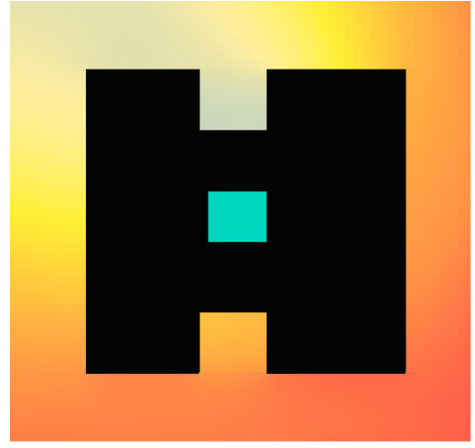

a) Floor plan of the courtyard

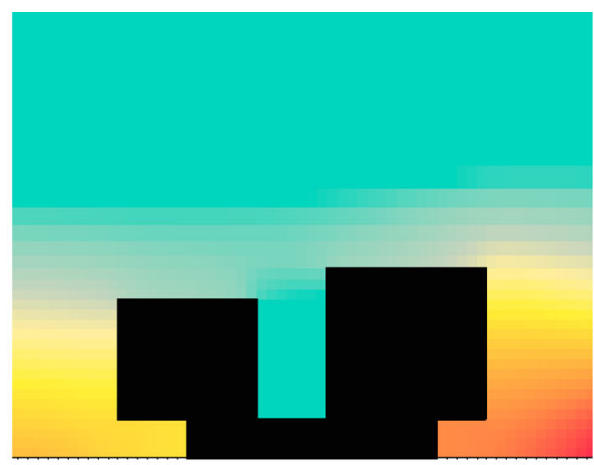

b) South-North section of the courtyard
Potential Air Temperature

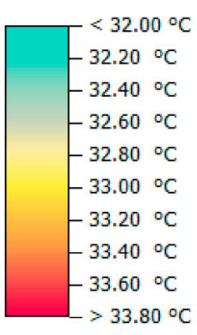

Min: $32.02{ }^{\circ} \mathrm{C}$ Max: $33.89^{\circ} \mathrm{C}$

Figure 11. ENVI-met simulation results on October $6^{\text {th }}, 2017$ at $4.00 \mathrm{pm}$.

considerable temperature reduction in the lowest part of the courtyard.

In this case, the radiation levels are similar for all walls. Consequently, the warm air is expanded uniformly along the upper part, although it can be observed that the north wall is warmer than the rest of the walls because the radiation is higher in that zone during the day.

Simulation time for the proposed model is four minutes per $24 \mathrm{~h}$ of simulations. This is much shorter than many of the existing tools, as it will be seen in the next sections.

\subsection{Comparison with ENVI-met simulation}

The simulation of the same days previously described has been carried out with ENVI-met, a widely used software for urban microclimate analysis. Air temperature results from this software have been represented in Figures 10-12.

The results show a tempering effect of the courtyard. However, the temperature difference between the courtyard and the outdoor is not as large as the monitored results showed. Furthermore, the software is not able to simulate the stratification effect that the courtyard produces. These results are in accordance with previous studies that showed that the simulation of spaces such as courtyards is not accurate enough using this software (López-Cabeza et al. 2018). The simulation time for $24 \mathrm{~h}$ of results is $15 \mathrm{~h}$ on average.

\subsection{Comparison with Ladybug tools}

Results from the simulation performed with the Ladybug Tools are shown in Figures 13 and 14. It shows that this software also overestimates the temperature in the courtyards the two simulated days. However, in contrast to the simulation with ENVI-met, it can predict the stratification in the courtyard, providing higher temperatures at higher levels of the courtyards, especially when the outdoor temperature is at its hotter hours. Simulation of Day 1 in August seems graphically closer to monitored data than Day 2 in October. This is probably explained by the higher wind speeds that day, which probably renovate the air in the courtyard at a higher rate, among other factors. The simulation time in this simulation was approximately $18 \mathrm{~h}$ for $24 \mathrm{~h}$ of simulation, although being a steady-state solver, it is possible to check hourly results without the calculation of the whole day. 

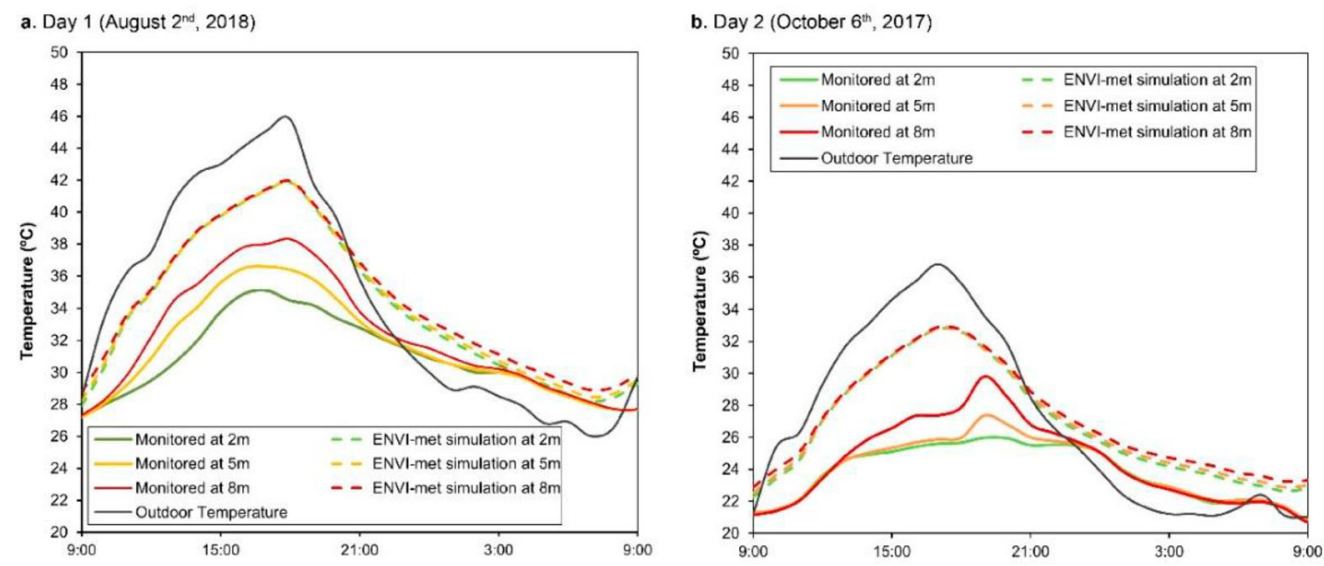

Figure 12. ENVI-met simulation results and monitoring. (a) Day 1 (August 2nd, 2018). (b). Day 2. (October 6th, 2017).

a. Day 1 (August $2^{\text {nd }}, 2018$ )

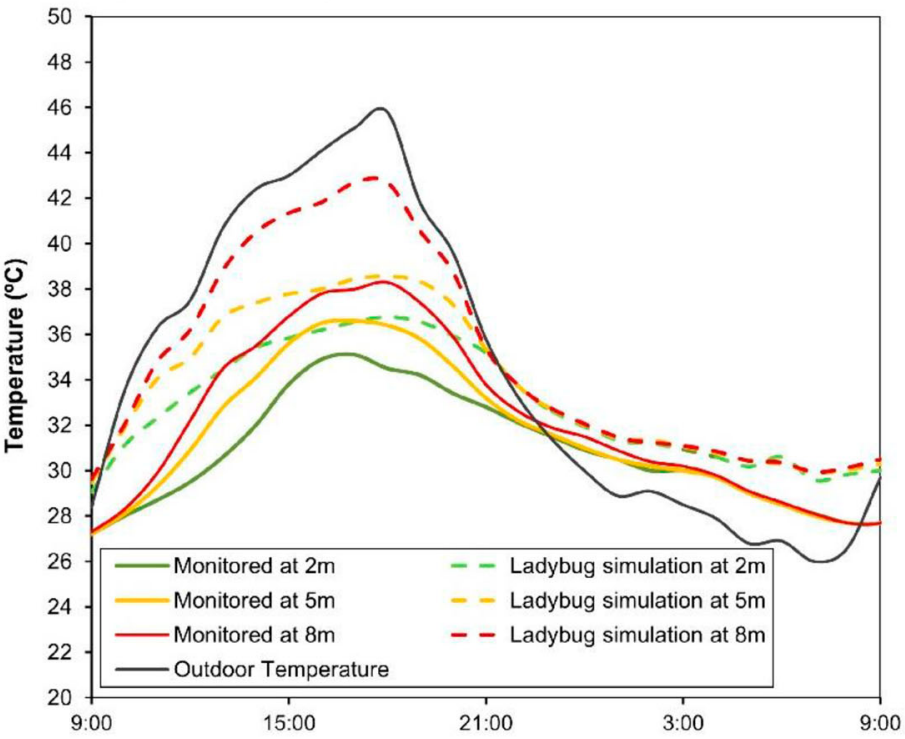

b. East-west section of the courtyard

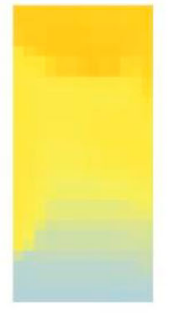

$12: 00$

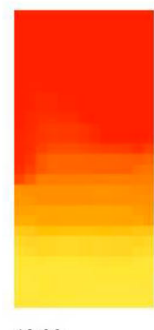

$18: 00$

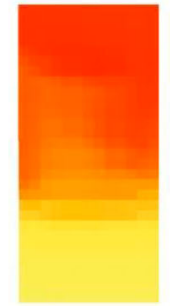

15:00

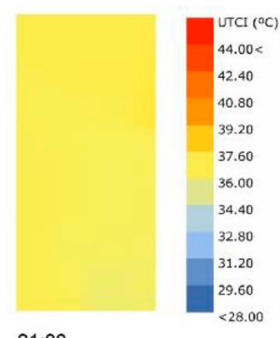

$21: 00$

Figure 13. Ladybug Tools simulation results and monitoring. (a) Day 1 (August 2nd, 2018). (b). East-west section of the courtyard.

\section{Discussion}

In this section, temperature results have been analysed using the statistical parameters described in section 3.3. Then, a discussion about the reasons for these differences is provided.

The value of the statistical parameters for the air temperature in the courtyard for each simulation and the two days analysed are shown in Table 8.

These values confirm that the model proposed is the most accurate of the tools analysed, except for the coefficient of determination on October $6^{\text {th }}, 2017$. However, some authors suggest that this is not the most effective parameter to evaluate a simulation (Willmott 1982). All the other parameters show better accuracy for the proposed model than those for the commercial software. Furthermore, CV(RMSE) and NMBE (\%) values are lower than
Table 8. Quantitative evaluation of the ENVI-met and FreeFEM model performances through the computation of R2, RMSE, CV(RMSE), and NMBE.

\begin{tabular}{llccrr}
\hline Software & \multicolumn{1}{c}{ Date } & $\mathrm{R}^{2}$ & $\mathrm{RMSE}\left({ }^{\circ} \mathrm{C}\right)$ & $\begin{array}{c}\text { CV(RMSE) } \\
(\%)\end{array}$ & \multicolumn{1}{c}{\begin{tabular}{c}
\multicolumn{1}{c}{ NMBE } \\
$(\%)$
\end{tabular}} \\
\hline ENVI-met & August 2nd, 2018 & 0.89 & 3.31 & 10.46 & -8.60 \\
& October 6 ${ }^{\text {th }}, 2017$ & 0.77 & 3.40 & 14.05 & -11.82 \\
Ladybug Tools & August 2nd, 2018 & 0.89 & 2.59 & 8.25 & -7.31 \\
& October 6 th $^{2}$, 2017 & 0.53 & 4.49 & 18.59 & -16.52 \\
FreeFEM model & August 2nd, 2018 & 0.88 & 1.19 & 3.75 & 1.72 \\
& October 6th, 2017 & 0.64 & 1.59 & 6.59 & 3.69
\end{tabular}

$30 \%$ and $10 \%$ respectively, being considered as validated by the ASHRAE guideline.

Results from ENVI-met also performs under the validation limits of the ASHRAE Guideline except for the 
a. Day 2 (October $\left.6^{\text {th }}, 2017\right)$

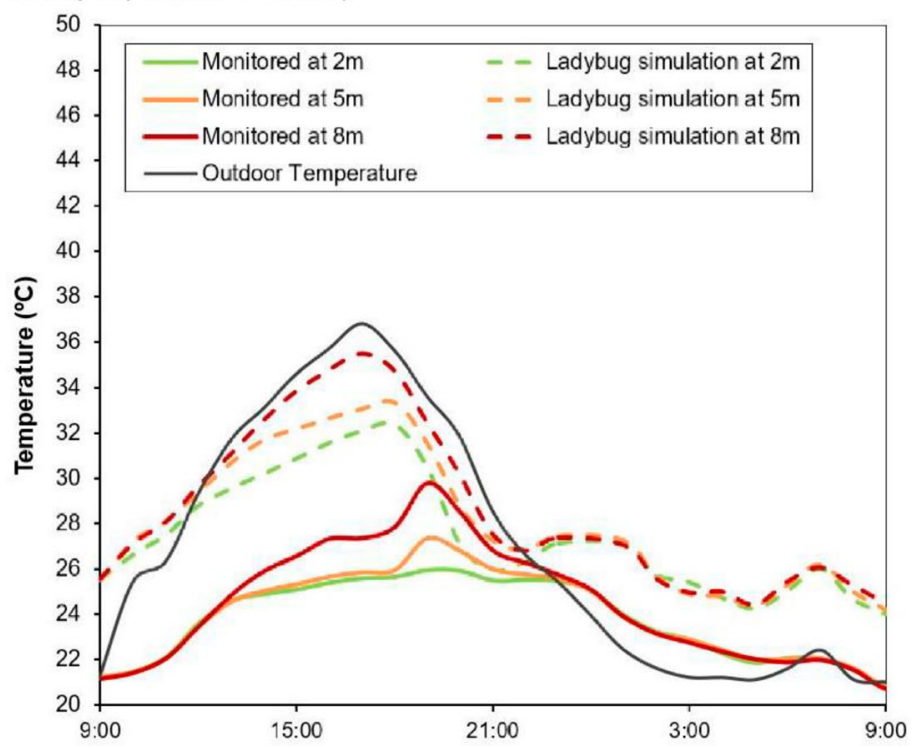

b. East-west section of the courtyard

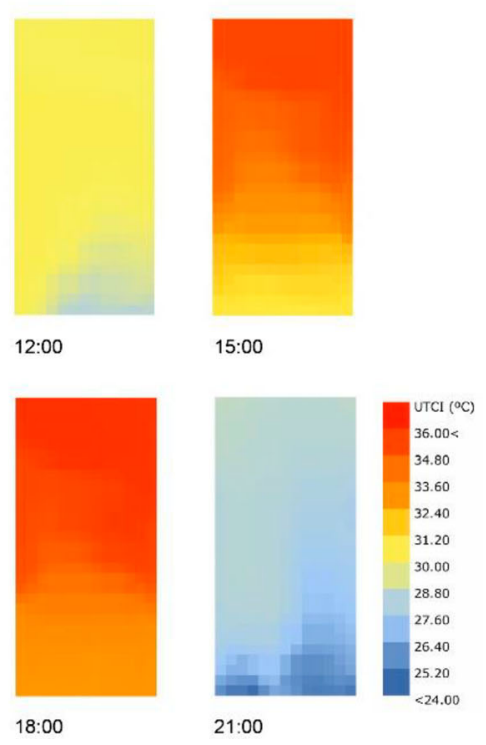

Figure 14. Ladybug Tools simulation results and monitoring. (a) Day 2 (October $6^{\text {th }}$, 2017). (b). East-west section of the courtyard.

NMBE in October. This means that the software is validated, although results are not as accurate as of the proposed model. The same situation occurs with the Ladybug results in October, providing an NMBE higher than $10 \%$.

The RMSE value gives an estimation of the mean error in Celsius. It can be seen that the model errors are 1.19 and $1.59^{\circ} \mathrm{C}$ for August and October respectively, being these values 3.31 and $3.40^{\circ} \mathrm{C}$ in ENVI-met and 2.59 and 4.49 in Ladybug Tools.

In conclusion, the errors obtained from the model are good and encourages its use for courtyard design and energy simulation.

The differences can be explained by the specific modelling of the thermal boundary layer and the thermal behaviour of the walls within the CFD model. Ladybug uses the outdoor temperature to calculate the surface temperature of the walls in the courtyard before performing the CFD calculation, thus, this is not accurate and the temperature in the courtyard is overestimated. ENVI-met grid cell size is too large to take into account the convection happening at the surface level of the walls. This can explain the better accuracy of our model.

In terms of simulation time, it must be noticed that the proposed model is specific for courtyard simulation, thus, the model domain is just the courtyard, in contrast to the other two models, where the domain is the whole building and it context. This explains the longer time for the existing tool simulations, requiring a higher computational cost.

\section{Conclusions}

This research develops a novel simulation tool to be used in the analysis of courtyard thermodynamic performance since available commercial tools are not able to accurately predict their microclimate conditions. A CFD model to simulate the courtyard air temperature and wall temperatures have been introduced. Its main innovation is a system of Ordinary Differential Equations (ODEs) at each grid node of the walls, governing the surface wall temperature and the inner wall temperature. To set up this system, we consider that the net heat transference term is active only when there is no solar radiation, taking into account the inverse radiation by the sky temperature. This ODEs system is coupled with the Boussinesq equations for natural convection flow.

The full model has been programmed with the FreeFEM software. Despite some simplifications required by the model, final results reproduce monitored data with higher accuracy than available existing tools. The model results show an RMSE of 1.19 and $1.59^{\circ} \mathrm{C}$ for August and October respectively, being these values 3.31 and $3.40^{\circ} \mathrm{C}$ in ENVI-met and 2.59 and 4.49 in Ladybug Tools. This higher accuracy is due to the specific modelling of the thermal boundary layer and the thermal behaviour of the walls within the CFD model.

This research has been focused on one case study, yet highly meaningful. The next goal is to better validate the mathematical model, by testing it in different courtyard geometries and climates, comparing monitored data with simulations. Once the mathematical model is validated, 
its introduction into energy performance software that predicts energy consumption in buildings is needed to take control of its microclimate during design. This will allow us to make better use of the passive strategy of courtyards, which can reduce outdoor temperatures up to $10^{\circ} \mathrm{C}$, with the consequent benefits to the overall energy performance of the architectural design.

\section{Acknowledgments}

The authors want to thank AEMET (Agencia Estatal de Metereología, State Meteorological Agency. Spanish Government) for the data supplied.

\section{Disclosure statement}

No potential conflict of interest was reported by the author(s).

\section{Funding}

This work was supported by the Ministerio de Economía y Competitividad, Gobierno de España (MTM2015-64577-C2-1-R/ MTM2015-64577-C2-2-R) and Ministerio de Ciencia, Innovación y Universidades (RTI2018-093521-B-C31/RTI2018-093521-B-C33). This publication was partially supported by Universidad de Sevilla (VI Plan Propio de Investigación y Transferencia, IUACC 2020). The authors thank the financial support of the Ministerio de Educación, Cultura y Deporte via a pre-doctoral contract granted to V.P. L-C. [grant number FPU17/05036].

\section{ORCID}

V.P. López-Cabeza (iD http://orcid.org/0000-0002-5257-1281

C. Galán-Marín (D) http://orcid.org/0000-0003-1929-3280

\section{References}

"Resúmenes Climatológicos - España - Anuales - Agencia Estatal de Meteorología - AEMET. Gobierno de España." 2018. Accessed March 21. http://www.aemet.es/es/serviciosclimati cos/vigilancia_clima/resumenes? $\mathrm{w}=0$ \&datos $=2$.

Abdulkareem, Haval A. 2016. "Thermal Comfort through the Microclimates of the Courtyard. A Critical Review of the Middle-Eastern Courtyard House as a Climatic Response." Procedia - Social and Behavioral Sciences 216 (October 2015) Elsevier B.V.: 662-674. doi:10.1016/j.sbspro.2015.12.054.

Acero, Juan A., and Karmele Herranz-Pascual. 2015. "A Comparison of Thermal Comfort Conditions in Four Urban Spaces by Means of Measurements and Modelling Techniques." Building and Environment 93 (P2) Elsevier Ltd: 245-257. doi:10.1016/j.buildenv.2015.06.028.

Antoniou, Nestoras, Hamid Montazeri, Marina Neophytou, and Bert Blocken. 2019. "CFD Simulation of Urban Microclimate: Validation Using High-Resolution Field Measurements." Science of the Total Environment 695 (December) Elsevier B.V.: 133743. doi:10.1016/j.scitotenv.2019.133743.

ASHRAE. 2014. ASHRAE Guideline 14-2014. Measurement of Energy, Demand, and Water Savings. https://energywatch-inc. com/ashrae-guideline-14/.

Benítez, M., and A. Bermúdez. 2011. "A Second Order Characteristics Finite Element Scheme for Natural Convection
Problems." Journal of Computational and Applied Mathematics 235 (11) North-Holland: 3270-3284. doi:10.1016/J.CAM.2011. 01.007.

Bermúdez, A. 2005. Continuouum Thermomechanics. Berlin: Birkhäuser Verlag.

Blocken, Bert, Ted Stathopoulos, Jan Carmeliet, and Jan L.M. Hensen. 2011. "Application of Computational Fluid Dynamics in Building Performance Simulation for the Outdoor Environment: An Overview." Journal of Building Performance Simulation 4 (2) Taylor \& Francis: 157-184. doi:10.1080/19401493. 2010.513740.

Chacón Rebollo, Tomás, Macarena Gómez Mármol, Frédéric Hecht, Samuele Rubino, and Isabel Sánchez Muñoz. 2018. “A High-Order Local Projection Stabilization Method for Natural Convection Problems." Journal of Scientific Computing 74 (2) Springer US: 667-692. doi:10.1007/s10915-017-0469-9.

Chandel, S. S., Vandna Sharma, and Bhanu M. Marwah. 2016. "Review of Energy Efficient Features in Vernacular Architecture for Improving Indoor Thermal Comfort Conditions." Renewable and Sustainable Energy Reviews 65 Elsevier: 459477. doi:10.1016/j.rser.2016.07.038.

Elwy, Ibrahim, Yasser Ibrahim, Mohammad Fahmy, and Mohamed Mahdy. 2018. "Outdoor Microclimatic Validation for Hybrid Simulation Workflow in Hot Arid Climates Against ENVI-Met and Field Measurements." Energy Procedia, doi:10.1016/j.egypro.2018.10.009.

"ENVI-Met.". 2019. Accessed October 28. https://www.envi-met. $\mathrm{com} /$.

Forouzandeh, Aysan. 2018. "Numerical Modeling Validation for the Microclimate Thermal Condition of Semi-Closed Courtyard Spaces between Buildings." Sustainable Cities and Society 36 (August 2017) Elsevier: 327-345. doi:10.1016/j.scs.2017. 07.025 .

"FreeFEM.". https://freefem.org/.

Ghaffarianhoseini, Amirhosein, Umberto Berardi, and Ali Ghaffarianhoseini. 2015. "Thermal Performance Characteristics of Unshaded Courtyards in Hot and Humid Climates." Building and Environment 87 Elsevier Ltd: 154-168. doi:10.1016/j.buil denv.2015.02.001.

Gresho, P. M., R. L. Lee, S. T. Chan, and R. L. Sani. 1980. “Solution of the Time-Dependent Incompressible Navier-Stokes and Boussinesq Equations Using the Galerkin Finite Element Method." Lecture Notes in Mathematics Series 771: 203-222. doi:10.1007/BFb0086908.

“Help: Green Building Studio Validation.” 2020. Accessed April 11. http://help.autodesk.com/view/BUILDING_PERFORMAN CE_ANALYSIS/ENU/?guid = GUID-EF68E7D5-COA5-4805-BFE5 -7C74C57B712E.

"Help: Weather Data in GBS." 2020. Accessed April 11. http://help .autodesk.com/view/BUILDING_PERFORMANCE_ANALYSIS/ ENU/?guid = GUID-66C3DCAE-B45D-4BFA-9916-9F1CD83 FC9EF.

IEA/UN. 2019. 2019 Global Status Report for Buildings and Construction: Towards a Zero-Emission, Efficient and Resilient Buildings and Construction Sector.

IPCC. 2014. Climate Change 2014: Synthesis Report, Contribution of Working Groups I, II and III to the Fifth Assessment Report of the Intergovernmental Panel on Climate Change. Geneva, Switzerland: IPCC. doi:10.1016/S0022-0248(00)00575-3.

Kottek, Markus, Jürgen Grieser, Christoph Beck, Bruno Rudolf, and Franz Rubel. 2006. "World Map of the Köppen-Geiger Climate Classification Updated." Meteorologische Zeitschrift 15 (3): 259-263. doi:10.1127/0941-2948/2006/0130. 
Kubota, Tetsu, Mohd Azuan Zakaria, Seiji Abe, and Doris Hooi Chyee Toe. 2017. "Thermal Functions of Internal Courtyards in Traditional Chinese Shophouses in the Hot-Humid Climate of Malaysia." Building and Environment 112 Elsevier Ltd: 115-131. doi:10.1016/j.buildenv.2016.11.005.

"Ladybug Tools | Home Page." 2020. Accessed September 4. https://www.ladybug.tools/.

López-Cabeza, V.P., C. Galán-Marín, C. Rivera-Gómez, and J. RoaFernández. 2018. "Courtyard Microclimate ENVI-Met Outputs Deviation from the Experimental Data." Building and Environment 144 (August) Elsevier: 129-141. doi:10.1016/j.buildenv. 2018.08.013.

Mackey, Christopher, Theodore Galanos, Leslie Norford, and Mostapha Sadeghipour Roudsari. 2017. "Wind, Sun, Surface Temperature, and Heat Island: Critical Variables for High-Resolution Outdoor Thermal Comfort." In Proceedings of the 15th IBPSA Conference San Francisco, CA, USA, 985-993. San Francisco, CA. doi:10.26868/25222708.2017. 260.

Mauree, Dasaraden, Emanuele Naboni, Silvia Coccolo, A. T. D. Perera, Vahid M. Nik, and Jean-Louis Scartezzini. 2019. "A Review of Assessment Methods for the Urban Environment and Its Energy Sustainability to Guarantee Climate Adaptation of Future Cities." Renewable and Sustainable Energy Reviews 112 (September) Pergamon: 733-746. doi:10.1016/J.RSER.2019.06.005.

Nasrollahi, Nazanin, Mojtaba Hatami, Seyedeh Razieyeh Khastar, and Mohammad Taleghani. 2017. "Numerical Evaluation of Thermal Comfort in Traditional Courtyards to Develop New Microclimate Design in a Hot and Dry Climate." Sustainable Cities and Society 35 (June) Elsevier: 449-467. doi:10.1016/j.scs.2017.08.017.

Rabinowitz, P. H. 1968. "Existence and Nonuniqueness of Rectangular Solutions of the Bénard Problem." Archive for Rational Mechanics and Analysis 29 (1) Springer-Verlag: 32-57. doi:10.1007/BF00256457.

Rojas-Fernández, Juan, Carmen Galán-Marín, Carlos RiveraGómez, and Enrique D. Fernández-Nieto. 2018. "Exploring the Interplay Between CAD and FreeFem ++ as an Energy Decision-Making Tool for Architectural Design." Energies 11 (10). doi:10.3390/en11102665.

Rojas-Fernández, Juan, Carmen Galán-Marín, Jorge RoaFernández, and Carlos Rivera-Gómez. 2017. "Correlations Between GIS-Based Urban Building Densification Analysis and Climate Guidelines for Mediterranean Courtyards." Sustainability (Switzerland) 9 (12). doi:10.3390/su9122255.

Rojas, Juan M., Carmen Galán-Marín, and Enrique D. FernándezNieto. 2012. "Parametric Study of Thermodynamics in the Mediterranean Courtyard as a Tool for the Design of EcoEfficient Buildings." Energies 5 (7): 2381-2403. doi:10.3390/en 5072381.

Sadeghipour Roudsari, Mostapha, Michelle Pak, and Adrian Smith. 2013. "Ladybug: A Parametric Environmental Plugin for Grasshopper To Help Designers Create an Environmental ly-Conscious Design." 13th Conference of International Building Performance Simulation Association, 3129-3135. http:// www.ibpsa.org/proceedings/bs2013/p_2499.pdf.

Salata, Ferdinando, lacopo Golasi, Roberto de Lieto Vollaro, and Andrea de Lieto Vollaro. 2016. "Urban Microclimate and Outdoor Thermal Comfort. A Proper Procedure to Fit ENVI-Met Simulation Outputs to Experimental Data." Sustainable Cities and Society 26 Elsevier B.V.: 318-343. doi:10.1016/j.scs.2016.07.005.

Santamouris, M., N. Papanikolaou, I. Livada, I. Koronakis, C. Georgakis, A. Argiriou, and D. N. Assimakopoulos. 2001. "On the Impact of Urban Climate on the Energy Consuption of Building." Solar Energy 70 (3): 201-216. doi:10.1016/S0038092X(00)00095-5.

Santamouris, M., and Geun Young Yun. 2020. "Recent Development and Research Priorities on Cool and Super Cool Materials to Mitigate Urban Heat Island." Renewable Energy 161 Elsevier Ltd: 792-807. doi:10.1016/j.renene.2020.07.109.

Schlichting, H., and K. Gertesten. 2004. Boundary Layer Theory. Berlin: Springer-Verlag.

Srebric, Jelena, Mohammad Heidarinejad, and Jiying Liu. 2015. "Building Neighborhood Emerging Properties and Their Impacts on Multi-Scale Modeling of Building Energy and Airflows." Building and Environment 91 Elsevier: 246-262. doi:10.1016/j.buildenv.2015.02.031.

Tsoka, S., A. Tsikaloudaki, and T. Theodosiou. 2018. "Analyzing the ENVI-Met Microclimate Model's Performance and Assessing Cool Materials and Urban Vegetation Applications-A Review." Sustainable Cities and Society 43 (August) Elsevier: 55-76. doi:10.1016/j.scs.2018.08.009.

Willmott, Cort J. 1982. "Some Comments on the Evaluation of Model Performance." Bulletin of the American Meteorological Society 63 (11): 1309-1313. doi:10.1175/1520-0477(1982)063 $<1309:$ SCOTEO $><1309:$ SCOTEO $>2.0 . C O ; 2$. 


\section{Appendices}

\section{Appendix A. Tables of monitored data}

Table A1. Air speed and direction inputs on August 2nd, 2018.

\begin{tabular}{|c|c|c|c|c|c|}
\hline Time & $\begin{array}{l}\text { Speed } \\
(\mathrm{km} / \mathrm{h})\end{array}$ & Direction & Time & $\begin{array}{l}\text { Speed } \\
(\mathrm{km} / \mathrm{h})\end{array}$ & Direction \\
\hline 02/08/2018 09:00 & 3 & NE & 02/08/2018 21:00 & 3 & SE \\
\hline 02/08/2018 09:20 & 3 & $\mathrm{~N}$ & 02/08/2018 21:20 & 3 & $\mathrm{~s}$ \\
\hline 02/08/2018 09:40 & 3 & $\mathrm{E}$ & 02/08/2018 21:40 & 3 & SW \\
\hline 02/08/2018 10:00 & 3 & $\mathrm{E}$ & 02/08/2018 22:00 & 3 & W \\
\hline 02/08/2018 10:20 & 3 & $\mathrm{~N}$ & 02/08/2018 22:20 & 3 & NW \\
\hline 02/08/2018 10:40 & 4 & $\mathrm{E}$ & 02/08/2018 22:40 & 3 & SW \\
\hline 02/08/2018 11:00 & 5 & $\mathrm{NE}$ & 02/08/2018 23:00 & 3 & $\mathrm{~S}$ \\
\hline 02/08/2018 11:20 & 4 & $\mathrm{~N}$ & 02/08/2018 23:20 & 3 & NE \\
\hline 02/08/2018 11:40 & 3 & SE & $02 / 08 / 201823: 40$ & 3 & SW \\
\hline 02/08/2018 12:00 & 4 & $\mathrm{E}$ & 03/08/2018 00:00 & 3 & W \\
\hline 02/08/2018 12:20 & 5 & $\mathrm{NE}$ & 03/08/2018 00:20 & 3 & NW \\
\hline 02/08/2018 12:40 & 3 & $\mathrm{E}$ & 03/08/2018 00:40 & 3 & NE \\
\hline 02/08/2018 13:00 & 4 & $\mathrm{NE}$ & 03/08/2018 01:00 & 3 & W \\
\hline 02/08/2018 13:20 & 3 & NE & 03/08/2018 01:20 & 3 & SE \\
\hline 02/08/2018 13:40 & 3 & $\mathrm{NE}$ & 03/08/2018 01:40 & 3 & SW \\
\hline 02/08/2018 14:00 & 3 & $\mathrm{NE}$ & 03/08/2018 02:00 & 3 & W \\
\hline 02/08/2018 14:20 & 6 & $\mathrm{E}$ & 03/08/2018 02:20 & 4 & W \\
\hline 02/08/2018 14:40 & 3 & $\mathrm{E}$ & 03/08/2018 02:40 & 4 & W \\
\hline 02/08/2018 15:00 & 4 & SE & 03/08/2018 03:00 & 4 & NE \\
\hline 02/08/2018 15:20 & 3 & $\mathrm{NE}$ & 03/08/2018 03:20 & 3 & W \\
\hline 02/08/2018 15:40 & 3 & $\mathrm{E}$ & 03/08/2018 03:40 & 3 & W \\
\hline 02/08/2018 16:00 & 5 & $\mathrm{E}$ & 03/08/2018 04:00 & 3 & W \\
\hline 02/08/2018 16:20 & 4 & $\mathrm{E}$ & 03/08/2018 04:20 & 3 & NW \\
\hline 02/08/2018 16:40 & 3 & $\mathrm{E}$ & 03/08/2018 04:40 & 4 & $\mathrm{E}$ \\
\hline 02/08/2018 17:00 & 4 & $\mathrm{E}$ & 03/08/2018 05:00 & 3 & $\mathrm{~N}$ \\
\hline 02/08/2018 17:20 & 4 & $\mathrm{E}$ & 03/08/2018 05:20 & 4 & $\mathrm{NE}$ \\
\hline 02/08/2018 17:40 & 3 & $\mathrm{~N}$ & 03/08/2018 05:40 & 4 & NW \\
\hline 02/08/2018 18:00 & 3 & SE & 03/08/2018 06:00 & 6 & W \\
\hline 02/08/2018 18:20 & 5 & $\mathrm{NE}$ & 03/08/2018 06:20 & 4 & NW \\
\hline 02/08/2018 18:40 & 4 & $\mathrm{E}$ & 03/08/2018 06:40 & 3 & SE \\
\hline 02/08/2018 19:00 & 4 & $\mathrm{E}$ & 03/08/2018 07:00 & 4 & $\mathrm{~s}$ \\
\hline 02/08/2018 19:20 & 3 & $\mathrm{NE}$ & 03/08/2018 07:20 & 3 & W \\
\hline 02/08/2018 19:40 & 4 & SE & 03/08/2018 07:40 & 3 & NE \\
\hline 02/08/2018 20:00 & 3 & $\mathrm{E}$ & 03/08/2018 08:00 & 3 & SW \\
\hline 02/08/2018 20:20 & 3 & SE & 03/08/2018 08:20 & 3 & NW \\
\hline 02/08/2018 20:40 & 3 & $\mathrm{E}$ & 03/08/2018 08:40 & 3 & $\mathrm{~s}$ \\
\hline
\end{tabular}


Table A2. Air speed and direction inputs on October $6^{\text {th }}, 2017$.

\begin{tabular}{|c|c|c|c|c|c|}
\hline Time & $\begin{array}{l}\text { Speed } \\
(\mathrm{km} / \mathrm{h})\end{array}$ & Direction & Time & $\begin{array}{l}\text { Speed } \\
(\mathrm{km} / \mathrm{h})\end{array}$ & Direction \\
\hline 06/10/2017 09:00 & 3.6 & NNW & 06/10/2017 21:00 & 6.1 & $S$ \\
\hline 06/10/2017 09:20 & 3.6 & NW & 06/10/2017 21:20 & 13.3 & $\mathrm{~s}$ \\
\hline 06/10/2017 09:40 & 3.6 & SW & 06/10/2017 21:40 & 6.1 & $\mathrm{~s}$ \\
\hline 06/10/2017 10:00 & 2.5 & SE & 06/10/2017 22:00 & 8.6 & SW \\
\hline 06/10/2017 10:20 & 2.5 & W & 06/10/2017 22:20 & 7.2 & SW \\
\hline 06/10/2017 10:40 & 3.6 & SE & 06/10/2017 22:40 & 7.2 & $\mathrm{~s}$ \\
\hline 06/10/2017 11:00 & 3.6 & $\mathrm{E}$ & 06/10/2017 23:00 & 3.6 & SE \\
\hline 06/10/2017 11:20 & 2.5 & SE & 06/10/2017 23:20 & 7.2 & SW \\
\hline 06/10/2017 11:40 & 3.6 & $\mathrm{E}$ & 06/10/2017 23:40 & 9.7 & ESE \\
\hline 06/10/2017 12:00 & 5.0 & SE & 07/10/2017 00:00 & 6.1 & SE \\
\hline 06/10/2017 12:20 & 2.5 & NW & 07/10/2017 00:20 & 7.2 & $S$ \\
\hline 06/10/2017 12:40 & 5.0 & $\mathrm{E}$ & 07/10/2017 00:40 & 13.3 & $S$ \\
\hline 06/10/2017 13:00 & 2.5 & NW & 07/10/2017 01:00 & 3.6 & $\mathrm{~N}$ \\
\hline 06/10/2017 13:20 & 2.5 & SW & 07/10/2017 01:20 & 12.2 & $\mathrm{~s}$ \\
\hline 06/10/2017 13:40 & 5.0 & $\mathrm{~S}$ & 07/10/2017 01:40 & 7.2 & $S$ \\
\hline 06/10/2017 14:00 & 5.0 & W & 07/10/2017 02:00 & 9.7 & SW \\
\hline 06/10/2017 14:20 & 5.0 & $\mathrm{~s}$ & 07/10/2017 02:20 & 5.0 & SW \\
\hline 06/10/2017 14:40 & 3.6 & W & 07/10/2017 02:40 & 9.7 & $\mathrm{~s}$ \\
\hline 06/10/2017 15:00 & 9.7 & W & 07/10/2017 03:00 & 7.2 & $\mathrm{~S}$ \\
\hline 06/10/2017 15:20 & 6.1 & SE & 07/10/2017 03:20 & 0.0 & NW \\
\hline 06/10/2017 15:40 & 6.1 & $\mathrm{E}$ & 07/10/2017 03:40 & 1.1 & $\mathrm{~N}$ \\
\hline 06/10/2017 16:00 & 6.1 & W & 07/10/2017 04:00 & 2.5 & $\mathrm{E}$ \\
\hline 06/10/2017 16:20 & 7.2 & $\mathrm{~S}$ & 07/10/2017 04:20 & 1.1 & NW \\
\hline 06/10/2017 16:40 & 3.6 & NE & 07/10/2017 04:40 & 2.5 & $\mathrm{~N}$ \\
\hline 06/10/2017 17:00 & 5.0 & SSE & 07/10/2017 05:00 & 1.1 & NW \\
\hline 06/10/2017 17:20 & 11.2 & $S$ & 07/10/2017 05:20 & 1.1 & NW \\
\hline 06/10/2017 17:40 & 12.2 & NW & 07/10/2017 05:40 & 2.5 & W \\
\hline 06/10/2017 18:00 & 11.2 & WNW & 07/10/2017 06:00 & 2.5 & SW \\
\hline 06/10/2017 18:20 & 13.3 & $S$ & 07/10/2017 06:20 & 2.5 & $\mathrm{E}$ \\
\hline 06/10/2017 18:40 & 22.0 & SW & 07/10/2017 06:40 & 3.6 & SE \\
\hline 06/10/2017 19:00 & 12.2 & SW & 07/10/2017 07:00 & 2.5 & $\mathrm{~N}$ \\
\hline 06/10/2017 19:20 & 9.7 & NW & 07/10/2017 07:20 & 2.5 & NW \\
\hline 06/10/2017 19:40 & 9.7 & SW & 07/10/2017 07:40 & 2.5 & NW \\
\hline 06/10/2017 20:00 & 7.2 & SW & 07/10/2017 08:00 & 2.5 & $\mathrm{~N}$ \\
\hline 06/10/2017 20:20 & 8.6 & W & 07/10/2017 08:20 & 2.5 & $\mathrm{~N}$ \\
\hline 06/10/2017 20:40 & 12.2 & $\mathrm{~s}$ & 07/10/2017 08:40 & 3.6 & NW \\
\hline 06/10/2017 21:00 & 6.1 & $\mathrm{~S}$ & 07/10/2017 09:00 & 2.5 & $\mathrm{E}$ \\
\hline
\end{tabular}


Table A3. Outdoor hourly air temperature and relative humidity, and courtyard mean temperature from the weather station on roof of building and sensors on August 2nd, 2018 and October $6^{\text {th }}, 2017$.

\begin{tabular}{|c|c|c|c|c|c|c|}
\hline \multirow[b]{2}{*}{ Hour } & \multicolumn{3}{|c|}{ Summer (02.08.2018) } & \multicolumn{3}{|c|}{ Autumn (06.10.2017) } \\
\hline & $\begin{array}{l}\text { Outdoor T. } \\
\left({ }^{\circ} \mathrm{C}\right)\end{array}$ & $\begin{array}{c}\text { Courtyard } \\
\text { Relative H. (\%) }\end{array}$ & $\begin{array}{l}\text { Courtyard } \\
\text { Mean T. }\left({ }^{\circ} \mathrm{C}\right)\end{array}$ & $\begin{array}{l}\text { Outdoor T. } \\
\left({ }^{\circ} \mathrm{C}\right)\end{array}$ & $\begin{array}{c}\text { Courtyard } \\
\text { Relative H. (\%) }\end{array}$ & $\begin{array}{c}\text { Courtyard } \\
\text { Mean T. }\left({ }^{\circ} \mathrm{C}\right)\end{array}$ \\
\hline 09:00 & 28.4 & 37.2 & 27.2 & 21.2 & 55.3 & 21.2 \\
\hline 10:00 & 33.5 & 36.7 & 28.1 & 25.4 & 41.2 & 21.4 \\
\hline $11: 00$ & 36.3 & 34.5 & 29.3 & 26.3 & 38.5 & 22.1 \\
\hline $12: 00$ & 37.5 & 33.8 & 30.9 & 29.4 & 34.7 & 23.5 \\
\hline $13: 00$ & 40.7 & 32.8 & 32.6 & 31.7 & 30.1 & 24.7 \\
\hline $14: 00$ & 42.4 & 27.5 & 33.9 & 33.1 & 27.5 & 25.3 \\
\hline $15: 00$ & 43.0 & 27.8 & 35.4 & 34.6 & 23.3 & 25.7 \\
\hline $16: 00$ & 44.1 & 24.4 & 36.4 & 35.7 & 21.4 & 26.1 \\
\hline $17: 00$ & 45.1 & 25.0 & 36.6 & 36.8 & 19.7 & 26.3 \\
\hline $18: 00$ & 45.8 & 26.8 & 36.4 & 35.6 & 21.3 & 26.5 \\
\hline 19:00 & 41.8 & 29.6 & 35.8 & 33.6 & 32.5 & 27.7 \\
\hline 20:00 & 39.6 & 32.3 & 34.6 & 31.8 & 29.7 & 27.1 \\
\hline 21:00 & 35.8 & 34.7 & 33.3 & 28.5 & 37.8 & 26.1 \\
\hline $22: 00$ & 33.2 & 36.7 & 32.3 & 26.6 & 36.2 & 25.9 \\
\hline 23:00 & 31.4 & 36.7 & 31.7 & 25.4 & 41.2 & 25.6 \\
\hline 00:00 & 30.0 & 36.3 & 31.1 & 23.9 & 53.6 & 25.1 \\
\hline 01:00 & 28.9 & 36.5 & 30.6 & 22.4 & 66.4 & 23.9 \\
\hline 02:00 & 29.1 & 37.0 & 30.2 & 21.6 & 74.9 & 23.2 \\
\hline 03:00 & 28.5 & 36.4 & 30.1 & 21.2 & 80.5 & 22.8 \\
\hline 04:00 & 27.9 & 34.5 & 29.7 & 21.2 & 80.1 & 22.3 \\
\hline 05:00 & 26.8 & 35.7 & 29.0 & 21.1 & 82.0 & 22.0 \\
\hline 06:00 & 26.9 & 35.3 & 28.5 & 21.6 & 82.3 & 22.0 \\
\hline 07:00 & 26.0 & 36.7 & 28.1 & 22.4 & 70.9 & 22.0 \\
\hline 08:00 & 26.6 & 38.4 & 27.7 & 21.1 & 69.5 & 21.6 \\
\hline 09:00 & 29.7 & 37.8 & 27.7 & 21.0 & 65.4 & 20.8 \\
\hline
\end{tabular}

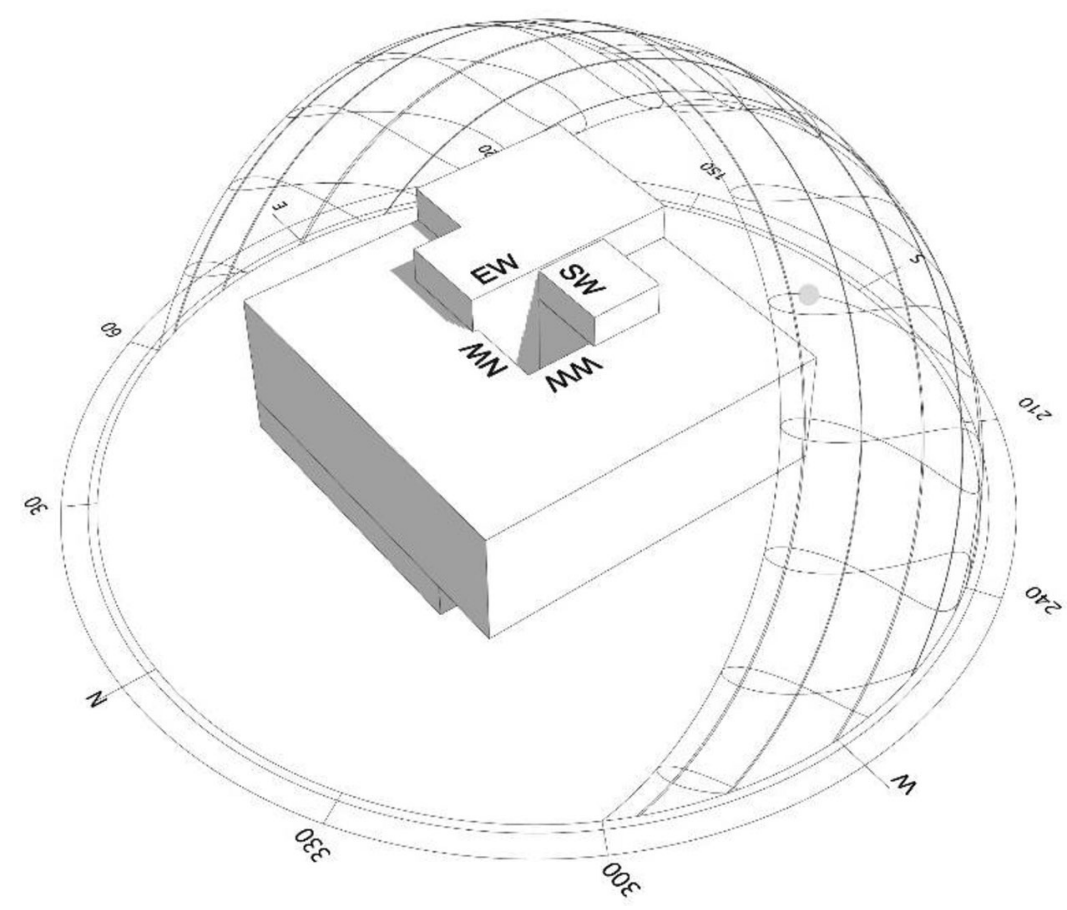

Figure A1. Sun path and shadow example in the courtyard on August 2nd at $16.00 \mathrm{~h}$. NW $=$ South wall. SW $=$ South wall. EW $=$ East wall. $\mathrm{WW}=$ West wall. 


\section{Appendix B. Global solar radiation in the walls of the courtyard}

Figure $A 2$ and Figure $A 3$ describe the global radiation at each point where the sensors had been located for each wall measured in the courtyard in the days selected for testing. Note that the time in hours are local time $(\mathrm{GTM}+2)$, and each graph represents one façade, each line corresponding to one height. It shows that solar radiation in August, reaching peaks at more than $500 \mathrm{~W} / \mathrm{m}^{2}$, is higher than in October, when peak radiation never overcomes $200 \mathrm{~W} / \mathrm{m} 2$.

Figure A1 shows the orientation of each façade and the geometry of the building, which explains the radiation results, affected by shadows produced by the geometry.

\section{Appendix C. Equations for error calculation:}

The following notation is used for the definition of the error measures:

$P_{i}$ is the forecast from the simulation method,

$P_{r}$ is the forecast from the least-squares regression

$O_{i}$ is the actual value at the monitoring,

$\bar{O}$ is the mean of the monitoring values, $\mathrm{n}$ is the number of series being summarized.

- Coefficient of determination:

$$
R^{2}=\frac{\sum_{i=1}^{n}\left(O_{i}-\overline{O_{i}}\right)\left(P_{i}-\overline{P_{i}}\right)}{\left[\sum_{i=1}^{n}\left(O_{i}-\overline{O_{i}}\right)^{2} \sum_{i=1}^{n}\left(P_{i}-\overline{P_{i}}\right)^{2}\right] 1 / 2}
$$

- Root Mean Square Error:

$$
R M S E=\left[\frac{\sum_{i=1}^{n}\left(P_{i}-O_{i}\right)^{2}}{n}\right]^{1 / 2}
$$

- Normalized Mean Bias Error:

$$
N M B E=\frac{\sum_{i=1}^{n}\left(O_{i}-P_{i}\right)}{(n-1) \bar{O}}
$$

- Coefficient of Variation of the Root Mean Square Error (CVRMSE)

$$
\mathrm{CV}(\mathrm{RMSE})=\frac{R M S E}{\bar{O}}
$$




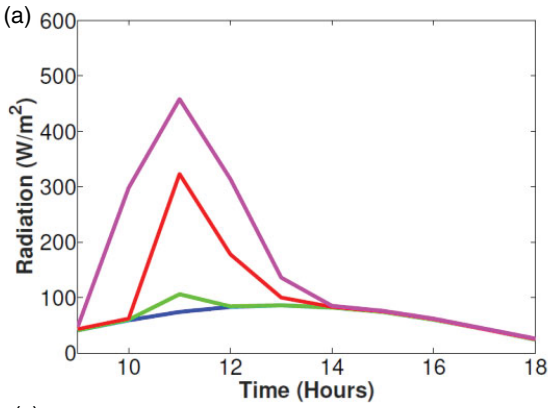

(c)

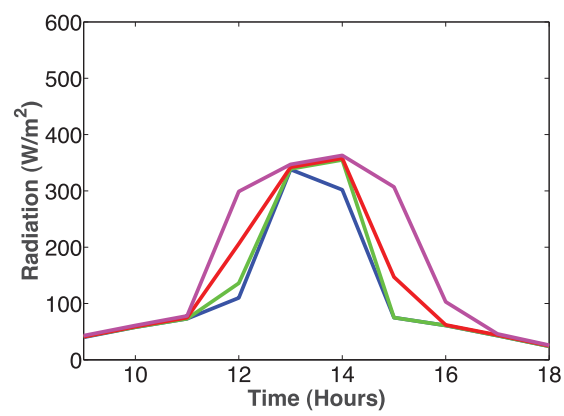

Figure A2. Input radiation on August 2nd, 2018.

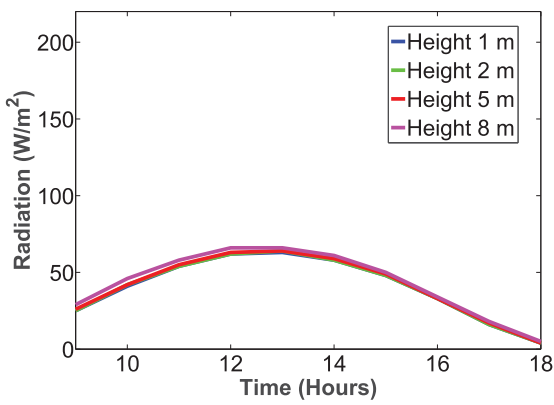

(a) West wall radiation

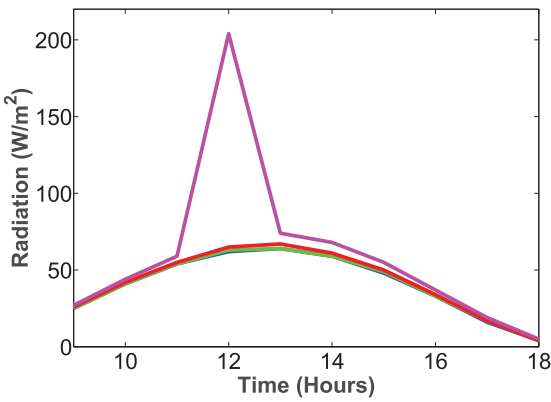

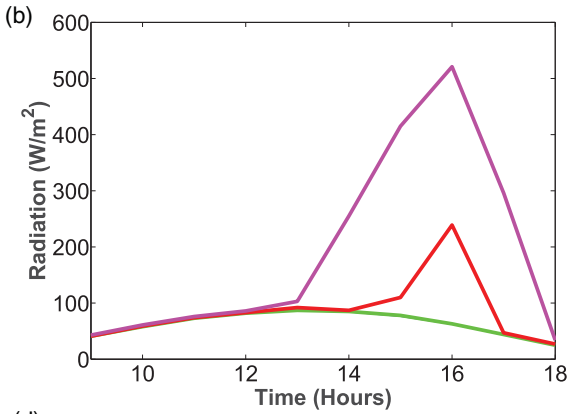

(d)

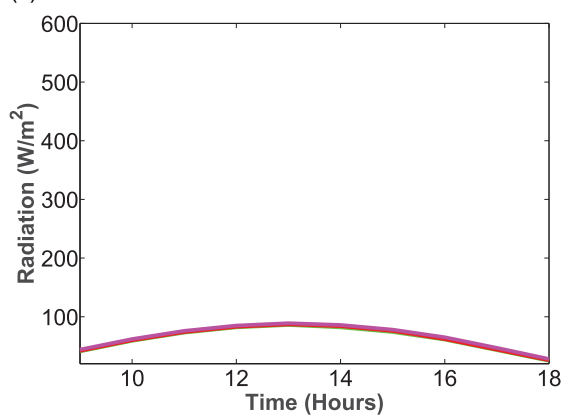

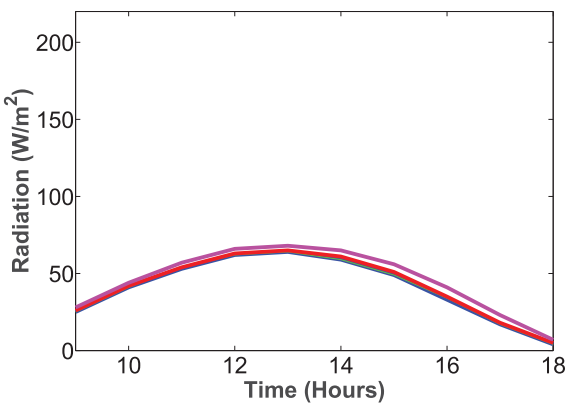

(b) East wall radiation.

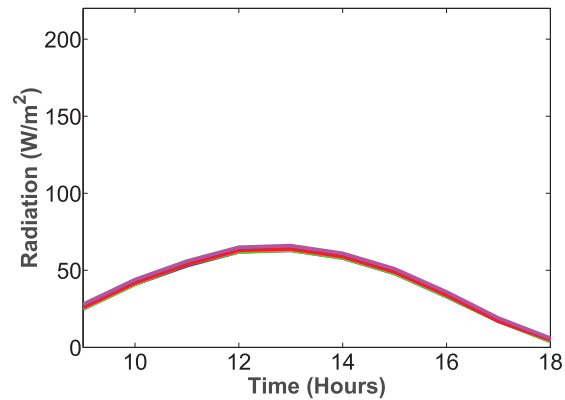

Figure A3. Input radiation on October $6^{\text {th }}, 2017$. 